\title{
Influence of $\mathrm{SO}_{2}$ on $\mathrm{CO}_{2}$ transport by pipeline for
}

\author{
carbon capture and storage (CCS) technology:
}

\section{Evaluation of $\mathrm{CO}_{2} / \mathrm{SO}_{2}$ co-capture}

Beatriz Gimeno, Manuela Artal, Inmaculada Velasco, Javier Fernández* and Sofía T. Blanco

Departamento de Química Física, Facultad de Ciencias, Universidad de Zaragoza, 50009

Zaragoza, Spain

ABSTRACT: $\mathrm{CO}_{2}$ capture and storage (CCS) is an important technology for avoiding atmospheric $\mathrm{CO}_{2}$ emissions, which are principally originated from fossil fuels combustion. Anthropogenic $\mathrm{CO}_{2}$ contains impurities that can strongly modify the properties of the stream. Several authors have showed that some of these impurities, such as $\mathrm{SO}_{2}$ present in emissions from sulfur containing fuels, could be favorable for some steps of the process, and the possibility of co-capture has been proposed. To assess this possibility with regard to the transport stage of CCS, we determined the influence of $\mathrm{SO}_{2}$ on selected parameters of transport by pipeline (minimal operational pressure, pressure and density drops, distance between boosters, booster power, and inner diameter of the pipeline and the Joule-Thomson coefficient). For this purpose, we obtained new and accurate experimental data for the density and vapor-liquid equilibrium of five $\mathrm{CO}_{2}+\mathrm{SO}_{2}$ mixtures under conditions of interest for CCS and speed of sound data for four of them. We compared our results with those found in the literature and with the values calculated 
using two equations of state for their validation: PC-SAFT and an extended version of EOS-CG that includes a binary model for the $\mathrm{CO}_{2}+\mathrm{SO}_{2}$ mixture. Allowing for the fact that chemical effects due to the presence of $\mathrm{SO}_{2}$, such as pipeline corrosion, have not been considered, we conclude that $\mathrm{CO}_{2} / \mathrm{SO}_{2}$ co-capture might favor and decrease the costs of the transport step of this technology, helping to avoid emissions of a highly toxic gas to the atmosphere without high desulfuration expenses.

\section{INTRODUCTION}

The globally averaged monthly mean concentration of $\mathrm{CO}_{2}$ in the atmosphere overtook the symbolic barrier of $400 \mathrm{ppm}$ in March 2015. ${ }^{1}$ This value is $15 \%$ higher than the recommended upper limit of $350 \mathrm{ppm}$ to avoid dangerous climate change..$^{2,3}$ Nonetheless, the annual mean global $\mathrm{CO}_{2}$ growth rates in 2015 and 2016 were the highest ever measured (3.01 and 2.98 $\mathrm{ppm} /$ year), and, after an increment of $1.95 \mathrm{ppm}$ in 2017 , the average $\mathrm{CO}_{2}$ concentration was 407.5 ppm in April 2018. ${ }^{1}$ The central aim of the Paris Agreement ${ }^{4}$ is to mitigate climate change by keeping the global temperature rise this century less than $2^{\circ} \mathrm{C}$ above pre-industrial levels ( 2 degrees scenario, 2DS). Moreover, this agreement pursues efforts to limit the temperature increase even further to $1.5^{\circ} \mathrm{C}$. At minimum, this scenario requires maintaining the global $\mathrm{CO}_{2}$ concentration below $450 \mathrm{ppm}$ throughout the century, ${ }^{5}$ but at the current rate of growth, this level will be reached before 2040 .

Emissions of $\mathrm{CO}_{2}$ from stationary sources arise mainly from fossil fuel combustion in the power generation sector, and significant amounts of $\mathrm{CO}_{2}$ are produced as well in the oil and gas processing industrial sectors. ${ }^{6}$ Given that the use of fossil fuels is not expected to decrease in the next few decades and that the production of anthropogenic $\mathrm{CO}_{2}$ is expected to grow, $\mathrm{CCS}$ (carbon capture and storage) appears to be one of the most important technologies for avoiding 
$\mathrm{CO}_{2}$ emissions to the atmosphere and thus mitigating climate change. In the case of the power generation sector, many sources have large emission volumes that make them amenable to the addition of $\mathrm{CO}_{2}$ capture technology. $\mathrm{CCS}$ consists of the capture of anthropogenic $\mathrm{CO}_{2}$ at the emitting power plants or industrial sites, its conditioning, its transport, and finally its injection and storage underground. $\mathrm{CO}_{2}$ capture can be achieved using different techniques, such as postcombustion, precombustion, and oxy-fuel combustion. Conditioning is carried out by dehydration, non-condensable gas separation and/or liquefaction, and compression-pumping. ${ }^{6-9}$ For transport, the use of high-pressure pipelines is accepted as the most practical method to move large amounts of $\mathrm{CO}_{2}$ over long distances. ${ }^{10-13}$ The fluid is transported in the dense or supercritical phase, thereby avoiding phase changes and two-phase flow, which produces cavitation and turbulence and reduces the quantity of fluid transported. ${ }^{14}$ Although transporting $\mathrm{CO}_{2}$ in the gaseous phase may be useful for low mass flow rates and short distances, ${ }^{15}$ this case was not considered in this work. The storage occurs in geological reservoirs, such as depleted oil and gas fields, deep saline aquifers or deep unmineable coal seams. ${ }^{16}$

It is impossible to implement least-cost emissions reduction scenarios, consistent with the Paris Agreement, that do not include wide deployment of CCS. ${ }^{5}$ International Energy Agency (IEA) and Global CCS Institute projections indicate that 2DS would require the capture and storage of approximately $4 \mathrm{Gt}$ per year of $\mathrm{CO}_{2}$ in 2040 , which is about 100 times the annual $\mathrm{CO}_{2}$ capture capacity expected to be in operation by 2018 ; in 2050 , the amount required to be stored will be of 5 Gt per year. ${ }^{17,18}$ To reach these targets, a rapid acceleration of current CCS deployment will be essential. First estimations indicate that between 200,000 and $360,000 \mathrm{~km}$ of high-pressure $\mathrm{CO}_{2}$ pipelines will be required worldwide in $2050 .{ }^{19}$ Comparatively, the currently existing 
network comprises approximately $6,500 \mathrm{~km}$ of pipelines, most of which are dedicated to enhanced oil recovery and located in the USA. ${ }^{20}$

It is well known that the fluid transported in these pipelines, anthropogenic $\mathrm{CO}_{2}$, contains impurities such as $\mathrm{N}_{2}, \mathrm{H}_{2}, \mathrm{O}_{2}, \mathrm{Ar}, \mathrm{SO}_{2}, \mathrm{NO}_{\mathrm{x}}, \mathrm{CO}, \mathrm{CH}_{4}$ and $\mathrm{H}_{2} \mathrm{O}$ that are derived from the emission sources and the capture and conditioning processes. ${ }^{21,22}$ The presence of these impurities, even at low concentrations, can strongly affect the properties of the fluid (density, $\rho$; vapor-liquid equilibrium, VLE; speed of sound, $c$; viscosity, $\eta$; etc.) and therefore the pipeline hydraulics and the design and operation of the pipeline network. Thus, knowledge of the properties of the impure stream is essential to determine the required purification level and to study the possibility of co-capturing impurities with $\mathrm{CO}_{2}$. Increasing the purity of $\mathrm{CO}_{2}$ could prevent potential risks such as pipeline corrosion and could provide streams with properties more similar to those of pure $\mathrm{CO}_{2}$; however, purification greatly increases the costs of the process. High-level purification is technically available but economically infeasible. ${ }^{8}$ Moreover, purification may not always be desirable. Several authors ${ }^{23-32}$ have suggested that the presence of certain impurities, such as $\mathrm{SO}_{2}$ generated in case of sulfur containing fuels, may favor some steps of the CCS process, mainly due to the effect of $\mathrm{SO}_{2}$ on the density and the Joule-Thomson coefficient of the fluid. Additionally, $\mathrm{CO}_{2} / \mathrm{SO}_{2}$ co-capture helps avoid the emission of $\mathrm{SO}_{2}$ into the atmosphere. Thus, the viability of the $\mathrm{CO}_{2} / \mathrm{SO}_{2}$ co-capture is an interesting issue worthy of being studied. However, we have not found literature reports on the effect of $\mathrm{SO}_{2}$ on the hydraulic and thermodynamic aspects of transport for CCS, and experimental data on the $\mathrm{CO}_{2}+\mathrm{SO}_{2}$ system are very limited. This could be due to the risks to researchers and facilities arising from the toxicity of $\mathrm{SO}_{2}$. 
This work is a part of a wider project that studies the feasibility of $\mathrm{CO}_{2} / \mathrm{SO}_{2}$ co-capture, focusing on the transport, injection and storage steps and on the simultaneous presence of other impurities, such as $\mathrm{CO}$ and $\mathrm{CH}_{4}$. Its first aim was to study those $\mathrm{CO}_{2}+\mathrm{SO}_{2}$ mixtures with compositions, temperatures and pressures of interest for CCS technology. We previously published two papers ${ }^{33,34}$ on experimentally determining the thermodynamic properties of these mixtures at temperatures and pressures relevant to injection and storage. We found that the presence of $\mathrm{SO}_{2}$ is profitable in most of the considered aspects (permeation flux, reservoir capacity, rising velocity of the plume inside deep saline aquifers and cooling during fluid expansion) especially in the case of shallow reservoirs. Now, in this work, the temperatures and pressures studied are relevant to the transport step. In this regard, we experimentally determined new and accurate pressure-density temperature, $p \rho T$, and VLE data for five $\mathrm{CO}_{2}+\mathrm{SO}_{2}$ mixtures, as well as $p c T$ for four of them (given that the speed of sound of the remaining mixture was previously published, ${ }^{33}$ although it is included in the discussion of this work). The studied compositions (mole fraction of $\mathrm{CO}_{2}, x_{\mathrm{CO}_{2}}$ ) range from 0.80 to 0.99 , including a proposed cocapture mixture of 0.95 that is particularly considered throughout this work. ${ }^{25}$ The working temperatures vary from 263 to $304 \mathrm{~K}$. Pressures reach up to $20 \mathrm{MPa}$ for densities and up to 190 MPa for speeds of sound. These ranges include the conditions of interest for the pipeline transport step of CCS and extend them to improve the knowledge of the behavior of the system and to reach the second aim of the work: equation of state $(\mathrm{EoS})$ validation over broader ranges than those found in CCS. Given the wide ranges of compositions, pressures and temperatures involved in CCS processes, an accurate predictive tool such as an EoS will be extraordinarily useful. In this paper, we contribute to finding such a predictive tool by comparing our experimental data with those provided by two EoS of different formulations: an extended EOS- 
CG, and PC-SAFT. ${ }^{35}$ The extended EOS-CG is a recent and unpublished version of the original EOS-CG $\mathrm{CG}^{36}$ that covers the $\mathrm{CO}_{2}+\mathrm{SO}_{2}$ mixture (absent in the original model) which is used as implemented in the TREND 2.0.1 software. ${ }^{37}$

The speed of sound of the $\mathrm{CO}_{2}+\mathrm{SO}_{2}$ mixtures with $x_{\mathrm{CO}_{2}} \geq 0.9$ can not be determined in our device, due to the acoustical opacity of $\mathrm{CO}_{2}$ at $5 \mathrm{MHz} .{ }^{33}$ To obtain proper signals, we doped the mixtures with small amounts of methanol, following a previously tested method. ${ }^{33}$ In the lowpressure range, where signals were not obtained despite the doping, we used our experimental data to obtain extrapolated speed of sound values, which were validated by comparisons with the values obtained from the EoS.

Finally, as the third aim of the work, we determined several parameters related to the transport step of CCS technology, and we demonstrated the effect of the presence of $\mathrm{SO}_{2}$ on them to evaluate the possibility of co-capture: minimum operational pressure; pressure and density drops along the pipeline, $p(d)$ and $\rho(d)$, respectively; maximum repressurization distance, $L$; power of the booster stations, $W$; and inner diameter of the pipeline, $D$. In addition, we calculated the Joule-Thomson coefficient, $\mu_{\mathrm{JT}}$, of the mixtures, which determines the thermal behavior of the fluid during depressurization, either operational or accidental, and is therefore important in both operations and hazard and risk studies.

Only the thermodynamic and hydraulic aspects were taken into account in this work; the chemical effects due to the presence of $\mathrm{SO}_{2}$, such as the possibility of pipeline corrosion, primarily in the presence of water, ${ }^{29,38-46}$ were not considered. It is well known that, while dry $\mathrm{CO}_{2}$ does not react with steel, the presence of water, even in small amounts, highly increases corrosion. Moreover, if the stream contains other impurities, they will contribute according to their nature and concentration. $\mathrm{SO}_{2}$, in presence of water, leads to sulfurous acid, and, in 
presence of oxygen, $\mathrm{SO}_{2}$ can be oxidized to sulfur trioxide and sulfuric acid can be formed. Even if it is clear that the presence of $\mathrm{SO}_{2}$ intensifies the corrosiveness of wet $\mathrm{CO}_{2}$, some authors have shown that corrosion is lower than expected, adducing principally the formation of protective layers of iron sulfate/sulfite hydrates ${ }^{40}$ and the low mobility of sulfuric acid in supercritical $\mathrm{CO}_{2}{ }^{42}$ In which authors agree is that the determining factor for corrosion is the amount of water, and some of them claim that reducing water content is a more favorable option compared to reducing $\mathrm{SO}_{2}$ content to minimize corrosion. ${ }^{46}$ Corrosion is important, but also other effects have to be considered. The assessment of the viability of $\mathrm{CO}_{2} / \mathrm{SO}_{2}$ co-capture must be carried out taking into account thermodynamic, hydraulic, and chemical effects. Conclusions must be derived from the balance of all of them, including technical, economic, and safety factors, as well as environmental considerations.

All the evaluations were performed in this work using new and accurate experimental values for the pressure-density-temperature composition, $p \rho T x_{\mathrm{CO}_{2}}$, and VLE and experimental and extrapolated values for the pressure-speed of sound-temperature-composition, $p c T x_{\mathrm{CO}_{2}}$, of $\mathrm{CO}_{2}$-rich mixtures containing $\mathrm{SO}_{2}$. Thus, to the best of our knowledge, this work constitutes sofar the most comprehensive study on the impact of $\mathrm{SO}_{2}$ on thermodynamic and hydraulic aspects of CCS transport based on experimental data. The results reported are necessary to establish the quality requirements/specifications of anthropogenic $\mathrm{CO}_{2}$ and to provide realistic values of the parameters needed for the safe and efficient design and operation of the pipeline network. All this information is essential to reach the needed deployment of CCS to accomplish the 2DS in the medium term. 


\section{EXPERIMENTAL SECTION}

2.1. Materials. Carbon dioxide and sulfur dioxide (mole fraction $>0.99998$ and 0.9990 , respectively) were purchased from Air Liquide and used as received. Methanol (biotech grade, mole fraction 0.9993) from Sigma Aldrich was degassed immediately before use.

2.2. Apparatus and methods. Given the toxicity of $\mathrm{SO}_{2}$, even in small amounts, and the inherent risk of working under high-pressure conditions, the laboratory was equipped with the necessary safety measures: all apparatuses were enclosed by safety polycarbonate panels, and fume hoods, gas masks, supplied-air hoods and gas detectors were used.

The mixtures were prepared in a variable volume cell manufactured by Top Industrie S.A.S. with a maximum volume of $0.51 \mathrm{~L}$ and a maximum working pressure of $30 \mathrm{MPa}$, as described previously. ${ }^{34}$ The components of the mixture were introduced into the cell in the order of increasing volatility. For mixtures with methanol (a dopant used, when necessary, for speed of sound determination), this component was added into the evacuated cell first and then degassed via intermittent vacuum with agitation for three hours. The masses of the different components were determined by successive weighing of the cell in a mass comparator Sartorius CCE 2004, with repeatability better than $0.0002 \mathrm{~g}$. The standard uncertainty in the mole fraction, $u_{x}$, was determined to be $2 \times 10^{-4}$. $^{34}$

To obtain the $p \rho T$ experimental data, we used an installation with an Anton Paar DMA HPM vibrating-tube densimeter connected to an MPDS V3 evaluation unit as the main component. ${ }^{47,48}$ It operates at temperatures $T$ from 263 to $423 \mathrm{~K}$ and at pressures $p$ from atmospheric pressure to $70 \mathrm{MPa}$. The temperature uncertainty, $u_{T}$, is of $0.006 \mathrm{~K}$ and the pressure uncertainty, $u_{p}$, is $0.0015 \mathrm{MPa}$ for $p<6 \mathrm{MPa}$ and $0.018 \mathrm{MPa}$ for $6 \mathrm{MPa} \leq p \leq 70 \mathrm{MPa}$. The probes used to measure 
the temperature were calibrated by the Centro Español de Metrología, $\mathrm{CEM},{ }^{49}$ and the pressure transducers were calibrated in our laboratories via a WIKA CPH 6000 calibrator. $^{34}$

The quasi-continuous acquisition of the data (approximately $6000 p \rho T$ points per isotherm, evenly reduced to approximately 1000 for easier handling) is achieved using a fluid flow of $0.005 \mathrm{MPa} \cdot \mathrm{s}^{-1}$, which allows measurements at thermodynamic quasi-equilibrium, as the designers of the apparatus indicate. ${ }^{50}$ A detailed explanation of apparatus and procedures can be found in previous publications. ${ }^{34,47,48}$ The high number of points with small separations allows the determination of the limits of the vapor-liquid equilibrium and the derivative properties from the experimental data.

The stability of the temperature during the measurement of each $p \rho T x_{\mathrm{CO}_{2}}$ isotherm was better than $\pm 0.05 \mathrm{~K}$. The experimental combined uncertainties in $\rho, u_{\rho}$, were calculated using the propagation uncertainty law according to the procedure detailed in a previous publication. ${ }^{34}$ These values are included in the tables of results, and their global average value was $0.49 \mathrm{~kg} \cdot \mathrm{m}^{-3}$. The procedure to determine the VLE limits, $p_{\text {dew }}$ and $p_{\text {bubble, }}$ and the densities of the vapor, $\rho_{\mathrm{V}}$, and liquid, $\rho_{\mathrm{L}}$, phases in the VLE and the calculation of their uncertainties were based on the methods proposed by the designers of the experimental setup ${ }^{50}$ and are explained elsewhewe. ${ }^{34}$ The combined uncertainties in the VLE data, which are reported in the tables of results, exhibit global average values of $0.017 \mathrm{MPa}$ for pressure and $1.1 \mathrm{~kg} \cdot \mathrm{m}^{-3}$ for density.

The speed of sound measurements were performed with an installation that employs a $5 \mathrm{MHz}$ pulsed ultrasonic system. ${ }^{33}$ It allows measurements in liquids and in compressed gases in the dense or supercritical phase. The main component is a dual-path ultrasonic cell located within a pressure vessel inside a thermostatic bath. The apparatus works from $253 \mathrm{~K}$ to $473 \mathrm{~K}$ with a 
temperature uncertainty, $u_{T}$, of $0.015 \mathrm{~K}$. The maximum achievable pressure is $200 \mathrm{MPa}$, and the $u_{p}$ is $0.02 \mathrm{MPa}$.

The mixtures with greater than 90 mole $\%$ of $\mathrm{CO}_{2}$ were found to be opaque to sound at $5 \mathrm{MHz}$. Consequently, we doped them with $\cong 0.8$ mole $\%$ methanol in order to obtain proper signals. This method was tested in a previous work. ${ }^{33}$ In that study, which was conducted on the $\mathrm{CO}_{2}+\mathrm{SO}_{2}$ mixture with $x_{\mathrm{SO}_{2}}=0.1032$ in the same $T$ and $p$ ranges as in this work, we showed that the difference in $c$ between the doped and the undoped mixtures is small in terms of experimental results $(0.17 \%$ on average $)$ and is negligible for modeling

The combined uncertainties in $c, u_{c}$, calculated using the propagation uncertainty law according to the procedure described in a previous paper, ${ }^{34}$ were $u_{c}=6.2 \times 10^{-4} c$ for $\mathrm{CO}_{2}+\mathrm{SO}_{2}$ and $u_{c}=8.1 \times 10^{-4} c$ for $\mathrm{CO}_{2}+\mathrm{CH}_{3} \mathrm{OH}+\mathrm{SO}_{2}$.

\section{RESULTS AND DISCUSSION}

The experimental and extrapolated thermodynamic results obtained in this work are shown in this section (subsection 3.1); they are subsequently compared to those calculated with the extended EOS-CG and PC-SAFT EoS in order to evaluate their predictive capability (3.2) and used to determine the influence of $\mathrm{SO}_{2}$ on several transport parameters (3.3) and on the JouleThomson coefficient of the fluid (3.4).

3.1. Results. We measured $20 p \rho T x_{\mathrm{CO}_{2}}$ isotherms (4 isotherms per mixture) for five $\mathrm{CO}_{2}+\mathrm{SO}_{2}$ mixtures $\left(\mathrm{CO}_{2}\right.$ mole fraction $x_{\mathrm{CO}_{2}}=0.8029,0.8969,0.9532,0.9698$, and 0.9931$)$ at temperatures $T=263.15,273.15,293.15$, and $304.21 \mathrm{~K}$ and pressures up to $20 \mathrm{MPa}$. This provides a total of $\cong 20,000$ points, which are available in the Supporting Information, SI, Table S1. A reduced number of points is presented in Table 1. The corresponding graphics are shown in Figures 1 and $\mathrm{S} 1$ (SI). The $T$ and $p$ ranges were chosen considering the operating conditions 
during transport by pipeline. ${ }^{20,51,52}$ The range of compositions encompasses a possible co-capture mixture ${ }^{25}\left(x_{\mathrm{CO}_{2}}=0.9532\right)$ and spans from a mixture with $x_{\mathrm{CO}_{2}}=0.8029$ to $\mathrm{CO}_{2}$-rich mixtures more similar to industrial emissions ${ }^{53,54}$ to extend the validation range for the EoS and enhance the general understanding of the impact of $\mathrm{SO}_{2}$.

The presence of $\mathrm{SO}_{2}$ increases the density of the mixture relative to that of pure $\mathrm{CO}_{2}{ }^{55}$ under all the studied conditions, and the $\rho$ values of the mixtures increase with increasing $x_{\mathrm{SO}_{2}}$ and pressure and with decreasing temperature. All the studied isotherms were subcritical, and we used the experimental data to obtain the dew and bubble pressures, $p_{\text {dew }}$ and $p_{\text {bubble }}$, and the densities of the phases in equilibrium for vapor, $\rho_{V}$, and liquid, $\rho_{\mathrm{L}}$. The results are collected in Table S2 and presented in Figures 2, S2 and S3. For comparison, Table S2 and Figure 2 also include the saturation pressures, phase densities, or critical data of pure $\mathrm{CO}_{2} .{ }^{55,56}$

In the literature, we found only one reference on experimental volumetric data for $\mathrm{CO}_{2}+\mathrm{SO}_{2}$ under the studied conditions. Nazeri et al. (2017) $)^{32}$ presents pressure-temperature-density data for a mixture with $x_{\mathrm{CO}_{2}}=0.9503$ at 273 and $283 \mathrm{~K}$, and for a mixture with $x_{\mathrm{CO}_{2}}=0.9478$ at 298 $\mathrm{K}$, at pressures up to approximately $42 \mathrm{MPa}$. The first composition is very close to our mixture with $x_{\mathrm{CO}_{2}}=0.9532$, even though the difference is higher than the experimental composition uncertainties reported in both works. The $273 \mathrm{~K}$ temperature is also very similar to one of this work $(273.15 \mathrm{~K})$, but again the difference is higher than the temperature uncertainties: Nazeri et al. measured nine experimental points in the vapor phase at $272.65 \mathrm{~K}$ and 77 points in the liquid phase between 273.54 and $273.60 \mathrm{~K}$. Our experimental density data (about 1000 experimental points, including both phases) were measured at $273.15 \pm 0.05 \mathrm{~K}$. The deviations, expressed as $M R D$, are very small along the coincident range of pressure: $0.85 \%$ for the vapor phase and 
$0.46 \%$ for the liquid phase, with an average value of $0.54 \%$. The rest of the data presented by Nazeri et al., even if not directly comparable, are in good agreement with ours.

About VLE experimental data, several references were found. ${ }^{32,34,57-62}$ The data from Coquelet et al. at 263.15 and $333.15 \mathrm{~K}^{62}$ are the only values reported by the NIST Standard Reference. ${ }^{63}$ Data at $263.15 \mathrm{~K}$, which are represented in Figures 2 and S2, include a bubble point and a dew point which can be compared exactly with our results since the temperatures and compositions match. The average difference in pressure is $1.3 \%$. The rest of the points from Coquelet et al. obtained at $263.15 \mathrm{~K}$ show good agreement with our data (Figures 2 and S2). Nazeri et al. ${ }^{32}$ give two bubble points for their mixture with $x_{\mathrm{CO}_{2}}=0.9503$, at 273.56 and $283.33 \mathrm{~K}$. At $273.56 \mathrm{~K}$, the reported bubble pressure is about $7 \%$ higher than our bubble pressure for $x_{\mathrm{CO}_{2}}=0.9532$ at 273.15 K (Figure 2). However, liquid phase densities at equilibrium are very similar, with a difference of $0.16 \%$. The values for both properties at $283.33 \mathrm{~K}$ are not directly comparable with ours, but they are in good agreement. The data from Gimeno et al. ${ }^{34}$ were measured at the same compositions and higher temperatures than ours and are in good agreement with our results (Figures S2, S3). Caubet ${ }^{58}$ determined several bubble points for a mixture with $x_{\mathrm{CO}_{2}}=0.8866$ at temperatures ranging from $295.15 \mathrm{~K}$ to $313.95 \mathrm{~K}$, as well as some dew points from $300.15 \mathrm{~K}$ to $322.95 \mathrm{~K}$ for the aforementioned mixture and from $299.15 \mathrm{~K}$ to $310.15 \mathrm{~K}$ for a mixture with $x_{\mathrm{CO}_{2}}=0.9265$. None of these points are directly comparable to those in this work because of the different composition and/or temperature, but they are consistent with our data. The VLE data from Bluemcke ${ }^{57}$ and Thiel et al. ${ }^{59}$ correspond to mixtures with more dilute $\mathrm{CO}_{2}$ than ours. The experimental data in Cummings ${ }^{60}$ and Lachet et al. ${ }^{61}$ are the same as those from Caubet ${ }^{58}$ and Coquelet et al., ${ }^{62}$ respectively. 
We determined $16 p c T x_{\mathrm{CO}_{2}}$ isotherms (four isotherms per mixture) for one $\mathrm{CO}_{2}+\mathrm{SO}_{2}$ and three $\mathrm{CO}_{2}+\mathrm{CH}_{3} \mathrm{OH}+\mathrm{SO}_{2}$ mixtures, all of which had the same $\mathrm{SO}_{2}$ mole fractions, $x_{\mathrm{SO}_{2}}$, as four of the five mixtures for which the density was determined $\left(x_{\mathrm{SO}_{2}}=0.1971,0.0468,0.0302\right.$, and 0.0069) at the same temperatures $T=263.15,273.15,293.15$, and $304.21 \mathrm{~K}$ and at pressures up to 190 $\mathrm{MPa}$ (Table S3, Figure 3, Figure S4). The data for the mixture with $x_{\mathrm{SO}_{2}}=0.1031$ were previously published, ${ }^{33}$ and they are discussed below. Given that the three mixtures with $x_{\mathrm{SO}_{2}}<$ 0.1 were essentially opaque to sound in most of the studied range of pressures, we doped them with $\cong 0.8$ mole $\%$ of methanol to obtain proper signals according to the method described in Rivas et al. (2016). ${ }^{33}$ The lower pressure limit of each isotherm was determined based on the point at which sound absorption became too large to receive the signal.

For each composition and temperature, a polynomial model was fitted to the experimental speed of sound measurements: ${ }^{33}$

$$
\left(p-p^{\#}\right)=\sum_{i=1}^{3} a_{i}\left(c-c^{\#}\right)^{i}
$$

where $p^{\#}$ is a reference pressure appropriate for each isotherm and $c^{\#}$ is the speed of sound at $p=$ $p^{\#}$. Table S4 shows the coefficients for eq. (1), the values of $p^{\#}$, and the mean relative deviations, $M R D_{c}(\%)$, between the experimental and fitted values. The overall mean relative deviation was $\overline{\overline{M R D_{c}}}=0.010 \%$, which is lower than the relative combined uncertainty of the experimental data. Most of the lowest values of pressure of the $p c T x_{\mathrm{CO}_{2}}$ isotherms are higher than the usual pressure range during transport by pipeline. For this reason, polynomials (1) with coefficients from Table S4 were used to extrapolate the $c$ values to the low-pressure region where no signal was obtained. The extrapolated values are reported in Table S5 and Figure 3 and were validated with the two studied EoS, as explained in the next section. 
The $c$ values in the mixtures vary with $T, p$ and $x_{\mathrm{SO}_{2}}$ in a similar way to the density, increasing with increasing $x_{\mathrm{SO}_{2}}$ and pressure and with decreasing temperature. We found no literature data for the speed of sound in the $\mathrm{CO}_{2}+\mathrm{SO}_{2}$ and $\mathrm{CO}_{2}+\mathrm{CH}_{3} \mathrm{OH}+\mathrm{SO}_{2}$ systems.

3.2. Comparison of the data with models. The fluids handled in CCS technology are $\mathrm{CO}_{2}$-rich mixtures with different impurities at variable concentrations and are used in wide ranges of pressure and temperature. Predictive tools such as EoS are required to obtain adequate knowledge of their properties. ${ }^{51,64-66}$ Recently, a new EoS based on the basic mathematical approach of the GERG $\operatorname{EoS}^{67}$ was developed principally for application to humid gases, combustion gases and $\mathrm{CO}_{2}$-rich mixtures of interest for CCS: the original EOS-CG mixture model. ${ }^{36}$ This original model does not include $\mathrm{SO}_{2}$. In this work, we evaluate both an unpublished extended EOS-CG that includes a binary model for the $\mathrm{CO}_{2}+\mathrm{SO}_{2}$ mixture and the PC-SAFT EoS,${ }^{35}$ which is widely used for calculations of thermodynamic properties, by comparing the values obtained from them with our experimental data. The differences are presented as the mean relative deviations, $M R D_{X}$. The methanol-doped mixtures used for $c$ measurements were modeled as pseudo-binary $\mathrm{CO}_{2}+\mathrm{SO}_{2}$ mixtures with the same $\mathrm{SO}_{2}$ concentrations: the mole fractions of $\mathrm{SO}_{2}$ used were those existing in the ternary mixtures, $x_{\mathrm{SO}_{2}}$, and the mole fractions of $\mathrm{CO}_{2}$ were considered to be $x_{\mathrm{CO}_{2}}=1-x_{\mathrm{SO}_{2}}$.

The EOS-CG was applied as implemented in TREND 2.0.1 software (Thermodynamic Reference \& Engineering Data). ${ }^{37}$ In TREND the original EOS-CG model of Gernert and Span ${ }^{36}$ is extended to additional minor components of typical CCS-mixtures. The implemented binary model for $\mathrm{CO}_{2}+\mathrm{SO}_{2}$ was developed at Ruhr University Bochum and is so-far unpublished. Due to the limited amount of experimental data that was available prior to our publication, the binary model contains only two adjusted parameters (of the temperature reducing function). For the $\mathrm{CO}_{2}$ 
and $\mathrm{SO}_{2}$ pure fluids, the model uses the Span and Wagner ${ }^{55}$ and the Gao et al. ${ }^{68}$ EoS respectively. The $M R D_{X}$ values are shown in Tables S6 and S7 and in Figures S5 and S6. The $M R D_{\rho}$ values decreased upon increasing the mole fraction of $\mathrm{CO}_{2}$ and did not show a clear trend with the temperature; the global average value was $\overline{\overline{M R D_{\rho}}}=0.54 \%$. Regarding the VLE, $\overline{\overline{M R D}} \bar{p}_{\text {dew }}=$ $2.07 \%, \overline{\overline{M R D}}_{p_{\text {bubble }}}=0.88 \%, \overline{\overline{M R D}}_{\rho_{V}}=2.91 \%$, and $\overline{\overline{M R D}}_{\rho_{L}}=0.73 \%$. The mean relative deviations on densities of the phases at equilibrium do not include the mixture with $x_{\mathrm{CO}_{2}}=$ 0.9931 at $304.21 \mathrm{~K}$. Although the dew and bubble pressures of this mixture are well reproduced (deviations of $0.87 \%$ and $0.61 \%$, respectively), the EoS shows anomalous behavior in the prediction of the phase densities with very high deviations from our experimental data $(25.6 \%$ for vapor and $9.46 \%$ for liquid), which is probably due to the close proximity to the critical point of the mixture. Figures 2, S2 and S3 include the experimental VLE data from this work and Coquelet et al. ${ }^{62}$ and those calculated from the extended EOS-CG at the studied temperatures. When we compared the deviations between our experimental $c$ data and those calculated by the EoS, we did not find remarkable trends with the temperature or composition, and the global average value was $\overline{\overline{M R D_{c}}}=0.40 \%$. For the extrapolated values, $\overline{\overline{M R D_{c}}}=0.39 \%$.

The calculations with the PC-SAFT EoS were performed using VLXE software. ${ }^{69}$ The methodology employed was previously described, ${ }^{33}$ and a volume translation parameter, $\Delta v_{c}$, was added to better reproduce the density values. ${ }^{34,70} \mathrm{We}$ took a binary interaction parameter from the literature ${ }^{71}$ since using a binary interaction parameter obtained from fitting our experimental data did not significantly modify the results. The pure compound parameters, the binary interaction parameters and the $\Delta v_{c}$ values are listed in Table $\mathrm{S} 8$, and the $M R D_{X}$ values are shown in Tables S6 and S7 and Figures S5 and S6. The $M R D_{\rho}$ increased with the increasing temperature, and there was no clear trend with the composition. The global average value was 
$\overline{\overline{M R D_{\rho}}}=0.56 \%$. Regarding the $V L E, \overline{\overline{M R D}}_{p_{\text {dew }}}=2.44 \%, \overline{\overline{M R}}_{p_{\text {bubble }}}=1.07 \%, \overline{\overline{M R}} \bar{\rho}_{\rho_{V}}=2.77 \%$, and $\overline{\overline{M R D}}_{\rho_{L}}=0.64 \%$. Comparison of the experimental VLE results with these EoS predictions is shown in Figures 2, S2 and S3. $M R D_{c}$ relative to the experimental results decreased with increasing $T$ and increased with increasing $x_{\mathrm{CO}_{2}}$ with a global average value of $\overline{\overline{M R} \overline{D_{c}}}=3.71 \%$. In the extrapolated results, $M R D_{c}$ increased with increasing $T$ and with decreasing $x_{\mathrm{CO}_{2}}$, and $\overline{\overline{M R D_{c}}}=3.70 \%$.

In a recent publication, $\mathrm{Xu}$ et al. ${ }^{72}$ presented thermodynamic calculations for the $\mathrm{CO}_{2}+\mathrm{SO}_{2}$ system using the PC-SAFT EoS but with different parameters from those utilized in this study. Comparing our experimental data with those calculated using the PC-SAFT EoS and the parameters from Xu et al., we found the following deviations: $\overline{\overline{M R D_{\rho}}}=0.93 \%, \overline{\overline{M R D}} \bar{p}_{\text {dew }}$ $=4.10 \%, \overline{\overline{M R D}}_{p_{\text {bubble }}}=1.82 \%, \overline{\overline{M R D}}_{\rho_{V}}=6.26 \%, \overline{\overline{M R D}}_{\rho_{L}}=0.71 \%$, and $\overline{\overline{M R D_{c}}}=2.46 \%$. These deviations were higher than those obtained using the parameters from Table S8, except for the deviation in speed of sound.

\subsection{Influence of $\mathrm{SO}_{2}$ on transport. Studies about the chemical effect of $\mathrm{SO}_{2}$ on the} transport of the CCS stream, especially in the presence of water, can be found in the literature. ${ }^{38-}$ ${ }^{46}$ However, we were unable to find studies about how $\mathrm{SO}_{2}$ influences pipeline design and operating parameters. In this work, we paid attention to the influence of the presence of $\mathrm{SO}_{2}$ on the transport of anthropogenic $\mathrm{CO}_{2}$ by pipeline. This was achieved by calculating the minimum operational pressure and several selected transport parameters related to this step of the CCS technology: pressure and density drops along the pipeline, $p(d)$ and $\rho(d)$; maximum repressurization distance (maximum separation distance between boosters), $L$; power of the booster stations, $W$; and inner diameter of the pipeline, $D$. These parameters, as well as other 
required ones (Reynolds number, $R e$; friction factor, $f$; and pressure drop per meter, $\Delta p / d$ ), were calculated using the equations presented in Table $S 9$, which have been reviewed and accepted by the industrial and engineering community. ${ }^{73,74}$ For these calculations, we used our experimental $\rho$ values, whereas the needed viscosity values of the mixtures were calculated using an improved extended corresponding states method for estimation of viscosity ${ }^{75}$ as implemented in the REFPROP 9.1 software ${ }^{76}$ due to the lack of experimental data. In addition, we calculated the Joule-Thomson coefficient, $\mu_{\mathrm{JT}}$, via the equations:

$$
\begin{aligned}
& \mu_{\mathrm{JT}}=\left(\frac{\partial T}{\partial p}\right)_{H}=\frac{V}{C_{p}}\left(\alpha_{p} T-1\right) \\
& C_{p}=\frac{\alpha_{p}^{2} T}{\rho\left(\kappa_{T}-\kappa_{S}\right)}
\end{aligned}
$$

where $V$ is the molar volume, $C_{p}$ is the heat capacity at constant pressure, and $\alpha_{p}, \kappa_{T}$, and $\kappa_{S}$ are the isobaric thermal expansivity and isothermal and isentropic compressibility, respectively. $\alpha_{p}$ was calculated from our experimental density data $(263.15 \mathrm{~K}-304.21 \mathrm{~K})$; to improve the calculations at the temperatures of the extremes of the interval, experimental values from Gimeno et al. ${ }^{34}$ at $313.15 \mathrm{~K}$ and values calculated using the extended EOS-CG at $253.15 \mathrm{~K}$ were also used. $\kappa_{T}$ was obtained from the experimental $\rho$ values, and $\kappa_{S}$ was determined from the experimental $\rho$ data and experimental and extrapolated $c$ data. For pure $\mathrm{CO}_{2}$, these properties were obtained using the reference EoS of Span and Wagner ${ }^{55}$ as implemented in REFPROP 9.1. ${ }^{76}$ The Joule-Thompson coefficient is necessary for understanding the thermal behavior of the fluid in pipeline depressurization or release (operational or accidental) because its value determines whether the stream cools or warms up upon pressure drop.

All the aforementioned factors must be considered in the design and operation of the pipeline network and balanced to obtain the most practical, safe, and cost-effective conditions. 
3.3.1. Minimum operational pressure. The estimated operating conditions of anthropogenic $\mathrm{CO}_{2}$ transport by pipeline range from 7.5 to $20 \mathrm{MPa}$ and from 273.15 to $303.15 \mathrm{~K} .{ }^{51}$ Some authors ${ }^{65,77}$ proposed an operating pressure above $8.6 \mathrm{MPa}$ to ensure that the fluid will always be in a single phase, dense or supercritical, over the whole range of temperatures that the anthropogenic $\mathrm{CO}_{2}$ in the pipeline may experience. Nevertheless, the lower limit for the operating pressure to avoid the undesired formation of a vapor phase is given by the bubble pressure of the fluid at the transport temperature (plus a margin for safety). Table S10 shows the $p_{\text {bubble }}$ and $\rho_{\mathrm{L}}$ of the studied mixtures, as well as the saturation pressures of pure $\mathrm{CO}_{2}$ at the same temperatures ${ }^{55}$ and the critical point of pure $\mathrm{CO}_{2} \cdot{ }^{56}$ Clearly, the presence of $\mathrm{SO}_{2}$ causes the bubble pressure of the fluid to diminish at a given temperature, allowing transport at lower pressures. The effect increases with increasing temperature. For the proposed co-capture mixture $\left(x_{\mathrm{CO}_{2}}=0.9532\right)$, the differences in pressure with respect to pure $\mathrm{CO}_{2}$ were $4.5 \%$ at $263.15 \mathrm{~K}$ and $7.2 \%$ at $293.15 \mathrm{~K}$.

Instead of a minimum pressure, other studies propose a minimum reference value for the density of the transported fluid, suggested to be $800 \mathrm{~kg} \cdot \mathrm{m}^{-3} \cdot{ }^{73,74}$ Fifteen of the twenty studied isotherms-isopleths present $\rho_{\mathrm{L}}$ values above $800 \mathrm{~kg} \cdot \mathrm{m}^{-3}$ (Tables $\mathrm{S} 2$ and $\mathrm{S} 10$ ). Because vapor phase formation must be avoided, recompression must be carried out before reaching the bubble pressure, even if the density of the fluid is higher than the reference value of $800 \mathrm{~kg} \cdot \mathrm{m}^{-3}$. Table $\mathrm{S} 10$ also includes the minimum experimental pressures to obtain densities $\geq 800 \mathrm{~kg} \cdot \mathrm{m}^{-3}$ avoiding vapor phase formation, $p_{800}$, and the densities at these pressures, $\rho_{800}$. We define $p_{\text {saf }}$ as the minimum safe operating pressure considered in this work, and $\rho_{\text {saf }}$ as the density at $p_{\text {saf }}$ (Table S10). If $\rho_{\text {saf }} \geq 800 \mathrm{~kg} \cdot \mathrm{m}^{-3}$, then $p_{\text {saf }}=p_{800}$. If $\rho_{\text {saf }}<800 \mathrm{~kg} \cdot \mathrm{m}^{-3}$, then $p_{\text {saf }}$ will be equal to $p_{\text {bubble }}$ plus a safety margin of $1 \mathrm{MPa}\left(p_{\text {saf }}=p_{\text {bubble }}+1 \mathrm{MPa}\right)$. For comparison, the same 
parameters determined for pure $\mathrm{CO}_{2}$ are also included. ${ }^{55,56} \mathrm{We}$ found that all the different pressure values shown in Table $\mathrm{S} 10$ for the mixtures are lower than those for pure $\mathrm{CO}_{2}$ at each temperature, thereby allowing transport at lower pressures, which is favorable for pipeline operation. The differences in $p_{\text {saf }}$ increase as the amount of $\mathrm{SO}_{2}$ and the temperature increase. For the co-capture mixture $x_{\mathrm{CO}_{2}}=0.9532$, we observed decreases in $p_{\text {saf }}$ compared to pure $\mathrm{CO}_{2}$ of $3.3 \%$ at $263.15 \mathrm{~K}$ and $6.1 \%$ at $293.15 \mathrm{~K}$.

3.3.2. Pressure, $p(d)$, and density, $\rho(d)$, profiles along the pipeline. The presence of impurities also affects the pressure drop-and therefore the density drop—along the pipeline. When the pressure or density reaches the minimum established values, repressurization is mandatory. In this paper, we work with two repressurization scenarios: when the pressure reaches a minimum value of $p_{\text {saf }}$ at each temperature (scenario $\mathrm{A}$, Table S10) and $8.50 \mathrm{MPa}$ (scenario B). Figures 4 and S7 show the pressure profiles, and Figures 5 and S7 show the density profiles as a function of the distance traveled by the stream.

We considered a pipeline with intermediate characteristics among those found in the literature,${ }^{20}$ namely, with an inner diameter $D=0.508 \mathrm{~m}$ (20 inches) and a capacity (mass flow) $m=317.1 \mathrm{~kg} \cdot \mathrm{s}^{-1}(10 \mathrm{Mt} / \mathrm{year})$. The inlet pressure, $p_{\text {in, }}$, was taken as $20.00 \mathrm{MPa}$, and the roughness height used was $4.6 \times 10^{-5} \mathrm{~m}(0.00015 \mathrm{ft}) .{ }^{52,73}$ No differences in altitude were taken into account in the route of the pipeline.

As seen in Figures 4, 5 and S7, both the pressure and density drop more slowly for the mixtures than for pure $\mathrm{CO}_{2}$, which is due to their density and viscosity values. The differences are higher at higher concentrations of $\mathrm{SO}_{2}$ and higher temperatures. For the co-capture mixture $\left(x_{\mathrm{CO}_{2}}=0.9532\right)$ at $293.15 \mathrm{~K}$ and a distance, $d$, of $300 \mathrm{~km}$, the pressure drops from 20.00 to 10.71 MPa (46\%); the density, from 964.7 to $900.9 \mathrm{~kg} \cdot \mathrm{m}^{-3}(6.6 \%)$. When the fluid is pure $\mathrm{CO}_{2}$, 
the pressure drops from 20 to $10.37 \mathrm{MPa}(48 \%)$; the density, from 937.1 to $860.7 \mathrm{~kg} \cdot \mathrm{m}^{-3}(8.2 \%)$. The slower decreases in the fluid pressure and density favor the transport operations because they allow the stream to travel a longer distance without repressurization.

3.3.3. Maximum repressurization distance, $L$, and booster station power, $W$. The pressure drop, itself a function of the inlet pressure, the diameter of the pipeline, the mass flow, and the properties of the transported fluid, determines the placement and number of pumping (booster) stations if necessary.

Figure 6 shows the maximum repressurization distance (maximum distance between boosters), $L$, versus the transport temperature, $T_{t r}$, in scenarios A and B. In both scenarios, the distance before repressurization is longer for the mixtures than for pure $\mathrm{CO}_{2}$, indicating that the transport of the mixtures is favored over that of pure $\mathrm{CO}_{2}$. The higher the mole fraction of $\mathrm{SO}_{2}$ and the temperature, the higher the difference in $L$ between the mixtures and pure $\mathrm{CO}_{2}$.

Comparing the two scenarios with each other shows that at low temperatures (below approximately $298 \mathrm{~K}$ ), the distances for repressurization $L$ are longer at $p_{\text {saf }}$ (scenario A) than at 8.5 MPa (scenario B). Nevertheless, between $\cong 298$ and $304 \mathrm{~K}$, the trend progressively reverses for pure $\mathrm{CO}_{2}$ and for the mixtures with $x_{\mathrm{CO}_{2}}=0.9931,0.9698$, and 0.9532. For the co-capture mixture at $293.15 \mathrm{~K}, L$ is $433.4 \mathrm{~km}$ in scenario A and $368.0 \mathrm{~km}$ in B; at $304.21 \mathrm{~K}$, the distances in scenarios A and B are $332.7 \mathrm{~km}$ and $346.1 \mathrm{~km}$, respectively.

Figure 7 presents the estimated booster power needed to repressurize the fluid up to a booster outlet pressure of $p_{\text {out }}=20.00 \mathrm{MPa}, W_{20}$, versus the booster inlet temperature, $T_{\mathrm{in}}$. It was assumed that $T_{\mathrm{in}}$ coincides with the transport temperature, $T_{\mathrm{tr}}$, and that the outlet temperature, $T_{\text {out }}$, is $38^{\circ} \mathrm{C}(311 \mathrm{~K}) .{ }^{66,74,77-79}$ The considered inlet pressure and density were those given by each of the above presented scenarios: either $p_{\text {in }}=p_{\text {saf }}$ and $\rho_{\text {in }}=\rho_{\text {saf }}$ (scenario A) or $p_{\text {in }}=$ 
8.50 MPa and $\rho_{\text {in }}=\rho_{8.50 \mathrm{MPa}}$ (scenario B). The booster efficiency was assumed to be $75 \% .{ }^{74} \mathrm{In}$ scenario A, $W_{20}$ decreases with increasing temperature. It also decreases with increasing $\mathrm{SO}_{2}$ mole fraction for temperatures up to $\cong 295 \mathrm{~K}$, but this trend reverses at higher temperatures. In scenario $\mathrm{B}, W_{20}$ increases with increasing temperature and decreasing $\mathrm{SO}_{2}$ concentration.

Below $\cong 298 \mathrm{~K}, W_{20}$ is always lower in scenario B than in $\mathrm{A}$; between $\cong 298$ and $304 \mathrm{~K}$, the trend reverses progressively for pure $\mathrm{CO}_{2}$ and for the mixtures with $x_{\mathrm{CO}_{2}}=0.9931,0.9698$, and 0.9532 .

In scenario A, the repressurization distances are always longer for the mixtures than for pure $\mathrm{CO}_{2}$ in the studied range of temperatures. Conversely, compared to pure $\mathrm{CO}_{2}$, the needed booster power is lower for the mixtures at temperatures below approximately $295 \mathrm{~K}$ but is higher at higher temperatures.

In scenario B, under all the studied conditions, the repressurization distances are longer for the mixtures than for pure $\mathrm{CO}_{2}$, and the booster powers are lower.

For the co-capture mixture $\left(x_{\mathrm{CO}_{2}}=0.9532\right)$ at $293.15 \mathrm{~K}$, repressurization must be performed at $L=433.4 \mathrm{~km}$ in scenario A and $L=368.0 \mathrm{~km}$ in scenario B compared to 405.2 and $354.9 \mathrm{~km}$, respectively, for pure $\mathrm{CO}_{2}$. The booster power needed is $W_{20}=6.68 \mathrm{MW}$ in scenario A and $W_{20}=$ 5.52 MW in scenario B for the mixture compared to 6.79 MW and 5.77 MW, respectively, for pure $\mathrm{CO}_{2}$.

3.3.4. Pipeline inner diameter, $D$. Figures $8, \mathrm{~S} 8$ and $\mathrm{S} 9$ show the inner diameter of a pipeline, $D$, versus its capacity (mass flow, $m$ ) for the mixtures and pure $\mathrm{CO}_{2}$ at the studied compositions and temperatures and at pressures of $8.50,15.00$, and 20.00 MPa. The capacity in the Figures ranges from 310 to $324 \mathrm{~kg} \cdot \mathrm{s}^{-1}$, an interval centered on the value used above for $m: 317.1 \mathrm{~kg} \cdot \mathrm{s}^{-1}=$ $10 \mathrm{Mt} / \mathrm{year}$. Diameters were iteratively calculated for each mass flow, repeating the calculation 
process until the difference between two successive runs was less than $0.1 \mathrm{~mm}$. An average pressure drop per meter of $30 \mathrm{~Pa} \cdot \mathrm{m}^{-1}$ and a roughness height of the pipeline of $4.6 \times 10^{-5} \mathrm{~m}$ were assumed..$^{52,73}$

The inner diameter needed to transport a given mass flow of fluid is lower for the mixtures than for pure $\mathrm{CO}_{2}$ because of their density and viscosity values, indicating the favorability of the transport of mixtures. The difference increases with increasing concentration of $\mathrm{SO}_{2}$ and temperature and decreasing pressure. For the co-capture mixture, the inner diameter needed for a flow of $317.1 \mathrm{~kg} \cdot \mathrm{s}^{-1}$ at $15.00 \mathrm{MPa}$ ranges from 0.499 to $0.517 \mathrm{~m}$ within the studied interval of temperatures. For pure $\mathrm{CO}_{2}$ under the same conditions, the diameters vary between 0.502 and $0.522 \mathrm{~m}$. At $293.15 \mathrm{~K}$ and $15.00 \mathrm{MPa}$, the inner diameter needed to transport $317.1 \mathrm{~kg} \cdot \mathrm{s}^{-1}$ of the co-capture mixture is $4 \mathrm{~mm}$ lower than that for pure $\mathrm{CO}_{2}$. For a pipeline made of standard carbon steel, API 5L X70, with an inner diameter of $511 \mathrm{~mm}$ and a wall thickness of $16.5 \mathrm{~mm},{ }^{13}$ this difference in inner diameter corresponds to a reduction of approximately $840 \mathrm{~kg}$ of steel per $\mathrm{km}$ of pipeline.

3.4. Joule-Thomson Coefficient, $\mu_{\mathrm{JT}}$. Figures 9 and $\mathrm{S} 10$ show the $\mu_{\mathrm{JT}}-p$ isotherms for the studied $\mathrm{CO}_{2}+\mathrm{SO}_{2}$ mixtures and pure $\mathrm{CO}_{2}$ at $273.15,293.15$ and $304.21 \mathrm{~K}$. The calculations at $263.15 \mathrm{~K}$ were not addressed due to the lack of the required experimental values at lower temperatures. In this section, composition is given as mole fraction of $\mathrm{SO}_{2}, x_{\mathrm{SO}_{2}}$, because in the calculations of $\mu_{\mathrm{JT}}$, we used densities measured in binary $\mathrm{CO}_{2}+\mathrm{SO}_{2}$ mixtures and speeds of sound determined in both binary $\mathrm{CO}_{2}+\mathrm{SO}_{2}$ and ternary (doped) $\mathrm{CO}_{2}+\mathrm{CH}_{3} \mathrm{OH}+\mathrm{SO}_{2}$ mixtures. The mole fraction of $\mathrm{SO}_{2}$ in the respective binary and ternary mixtures is the same. $\mu_{\mathrm{JT}}$ is lower for the mixtures than for pure $\mathrm{CO}_{2}$ at each temperature. At a given temperature, $\mu_{\mathrm{JT}}\left(\mathrm{CO}_{2}\right)-$ 
$\mu_{\mathrm{JT}}$ (mixture) increases with increasing concentration of $\mathrm{SO}_{2}$ in the mixture. For a given concentration of $\mathrm{SO}_{2}, \mu_{\mathrm{JT}}\left(\mathrm{CO}_{2}\right)-\mu_{\mathrm{JT}}($ mixture $)$ increases with increasing temperature.

At 293.15 and $304.21 \mathrm{~K}, \mu_{\mathrm{JT}}$ is positive for all the studied compositions and pressures, and the fluid cools under depressurization. At $273.15 \mathrm{~K}$, the four most $\mathrm{SO}_{2}$-rich mixtures, i.e., $x_{\mathrm{SO}_{2}}=$ $0.1971,0.1031,0.0468$, and 0.0302, exhibited experimental inversion pressures (coolingwarming change) of 10.8, 16.1, 19.6 and 20.3 MPa, respectively, which are the pressures below which the coefficients are positive and above which they are negative. Extrapolation of the results for the $x_{\mathrm{SO}_{2}}=0.0069$ mixture provides an inversion pressure of $21.6 \mathrm{MPa}$.

Figures 9 and S10 also include the values of $\mu_{\mathrm{JT}}$ calculated with the extended EOS-CG and the PC-SAFT EoS for the mixtures and those found in the literature for pure $\mathrm{CO}_{2} .{ }^{55}$ Table S11 presents for each isotherm the deviations between the experimental values and those calculated using the respective EoS in terms of the average absolute deviation, $\overline{A A D}_{\mu_{\mathrm{JT}}}$. The global average values of the deviations were $0.025 \mathrm{~K} \cdot \mathrm{MPa}^{-1}$ for extended EOS-CG and $0.027 \mathrm{~K} \cdot \mathrm{MPa}^{-1}$ for PCSAFT.

Figure 10 shows the inversion line for pure $\mathrm{CO}_{2}{ }^{55}$ and the inversion pressures at $273.15 \mathrm{~K}$ for the five mixtures. The presence of $\mathrm{SO}_{2}$ shifts the inversion points to lower pressures: the higher the $\mathrm{SO}_{2}$ concentration, the lower the inversion pressure. Figure 11 presents the inversion pressures at $273.15 \mathrm{~K}$ as a function of the $\mathrm{SO}_{2}$ mole fraction, showing a good linear correlation.

\section{CONCLUSIONS}

Some authors proposed that the presence of $\mathrm{SO}_{2}$ in the stream could favor some steps of CCS technology and thus proposed $\mathrm{CO}_{2} / \mathrm{SO}_{2}$ co-capture. To assess this possibility, we determined the impact of the presence of $\mathrm{SO}_{2}$ on several transport parameters and on the Joule-Thomson coefficient, which are required for the safety and profitability of CCS technology. For this 
purpose, we determined the densities and vapor-liquid equilibria data of five $\mathrm{CO}_{2}$-rich $\mathrm{CO}_{2}+\mathrm{SO}_{2}$ mixtures under conditions which include those of interest for CCS: $0.80 \leq x_{\mathrm{CO}_{2}} \leq 0.99,263.15$ $\leq T \leq 304.21 \mathrm{~K}$, and pressures up to $20 \mathrm{MPa}$. Similarly, we determined the speeds of sound for four of these mixtures at the same temperatures and at pressures up to $190 \mathrm{MPa}$ (the speed of sound of the remaining mixture was previously published). For the $c$ measurements, the mixtures with $x_{\mathrm{CO}_{2}}>0.90$ were doped with $\cong 0.8$ mole $\%$ of methanol to obtain proper signals. Suitable polynomials were fitted to the experimental results for the speed of sound and extrapolated to the low-pressure zone, where despite the doping, no signals were detected. The combined uncertainties obtained for the experimental results were as follows: average $u_{\rho}=0.49 \mathrm{~kg} \cdot \mathrm{m}^{-3}$; average $u_{p_{d}, p_{b}}=0.017 \mathrm{MPa}$; average $u_{\rho_{V}, \rho_{L}}=1.05 \mathrm{~kg} \cdot \mathrm{m}^{-3} ; u_{c}=6.2 \times 10^{-4} c$ for $\mathrm{CO}_{2}+\mathrm{SO}_{2}$ and $u_{c}=8.1 \times 10^{-4} c$ for $\mathrm{CO}_{2}+\mathrm{CH}_{3} \mathrm{OH}+\mathrm{SO}_{2}$. Only one reference with volumetric data for the studied mixtures and conditions was found in the literature, which is in good agreement with our results. Three original references were found on vapor-liquid equilibrium, most of them in good agreement with our results. No data were found on speed of sound of the studied systems.

The mixtures were modeled using the extended EOS-CG model as implemented in TREND 2.0.1. and the PC-SAFT equation of state. From the obtained deviations, we concluded that PCSAFT with the parameters shown in Table S8, and extended EOS-CG properly reproduce the measured properties of the $\mathrm{CO}_{2}+\mathrm{SO}_{2}$ system under these operating conditions, which include those of interest for CCS. The extended EOS-CG reproduces the speed of sound better than the PC-SAFT EoS. However, extended EOS-CG provides anomalous predictions for the density of the phases at equilibrium for the most $\mathrm{CO}_{2}$-rich mixture under conditions near its critical point. By comparing the extrapolated $c$ values with those obtained with both equations of state, we validated our extrapolated results for the speed of sound. 
Using our experimental data and viscosities from literature, we calculated selected parameters related to the transport of the studied $\mathrm{CO}_{2}+\mathrm{SO}_{2}$ mixtures by pipeline and compared them with those determined for pure $\mathrm{CO}_{2}$ to assess the convenience of transport $\mathrm{CO}_{2}$ containing $\mathrm{SO}_{2}$. We found that the presence of $\mathrm{SO}_{2}$ favors some aspects of the transport step compared to pure $\mathrm{CO}_{2}$ : it reduces the minimum operational pressure, the pressure and density drops along the pipeline, and the inner diameter needed to transport a given mass flow, and it increases the distance allowed between boosters at all the studied pressures and temperatures. The needed booster power for repressurization is lower for the mixtures than for pure $\mathrm{CO}_{2}$ at all the studied compositions and temperatures when the repressurization is conducted at a minimum pressure of 8.50 $\mathrm{MPa}$ (scenario B). The scenario A considered in this work consists in repressurizing when the density of the fluid reaches a minimum value of $800 \mathrm{~kg} \cdot \mathrm{m}^{-3}$, always keeping a minimum safety margin of $1 \mathrm{MPa}$ above the bubble pressure. In scenario A, the booster power for the mixtures is lower than that for pure $\mathrm{CO}_{2}$ below approximately $295 \mathrm{~K}$ but becomes higher at higher temperatures. At low temperatures, repressurization in scenario A enables longer distances between boosters than repressurization at $8.50 \mathrm{MPa}$, but it demands higher booster power; at high temperatures, the opposite behavior is observed. Regarding the repressurization distance, scenario A is clearly more sensitive to composition and temperature than scenario B.

We calculated the Joule-Thomson coefficients of the mixtures at 273.15, 293.15 and $304.21 \mathrm{~K}$. These values were lower than those for pure $\mathrm{CO}_{2}$, leading to a lower cooling of the anthropogenic $\mathrm{CO}_{2}$ containing $\mathrm{SO}_{2}$ during expansion. The differences increase with increasing $\mathrm{SO}_{2}$ concentration and temperature. At 293.15 and $304.21 \mathrm{~K}$, the obtained $\mu_{\mathrm{JT}}$ values were positive, which indicates fluid cooling under expansion. At $273.15 \mathrm{~K}$, the experimental inversion 
pressures of the mixtures were in the range from 10.8 to $21.6 \mathrm{MPa}$, and the higher the $\mathrm{SO}_{2}$ concentration, the lower the inversion pressure.

At $293.15 \mathrm{~K}$, a mixture containing 5 mole $\%$ of $\mathrm{SO}_{2}$ presents, a reduction of $6.1 \%$ in the minimum transport pressure compared to pure $\mathrm{CO}_{2}$ if repressurizations are accomplished $1 \mathrm{MPa}$

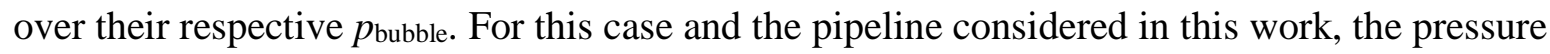
and density drops at $300 \mathrm{~km}$ reduce by $1.6 \%$. Moreover, the distance between boosters decreases by $6.9 \%$ and $3.7 \%$ in scenarios $A$ and $B$ respectively, and the booster power reduces by $1.6 \%$ and $4.0 \%$, respectively. In addition, the requirement of a lower diameter leads to a reduction of 840 $\mathrm{kg}$ of steel per km of pipeline. Finally, the Joule-Thomson coefficients for this co-capture mixture show reductions up to $35 \%$ over the studied ranges of $T$ and $p$, resulting in less cooling during expansion.

Authors concluded in a previous paper that the impact of $\mathrm{SO}_{2}$ on hydraulic and thermodynamic aspects of injection and storage is also beneficial. The conclusions of both works would indicate that $\mathrm{CO}_{2} / \mathrm{SO}_{2}$ co-capture may be a viable technology to lower the costs in CCS and to mitigate the emission of $\mathrm{SO}_{2}$ to the atmosphere. Nevertheless the possibility of corrosion, induced geochemical reactions, and risks associated with potential leakage from the pipeline network or the storage reservoirs were not included in our studies. The global conclusions must be derived from the balance of technical, economic and safety factors, as well as environmental considerations. 


\section{TABLES}

Table 1. $p \rho T x_{\mathrm{CO}_{2}}$ experimental data for the $\mathrm{CO}_{2}+\mathrm{SO}_{2}$ mixtures. $u_{\rho}$ : combined uncertainty.

\begin{tabular}{|c|c|c|c|c|c|c|c|c|c|c|c|}
\hline \multicolumn{12}{|c|}{$x_{\mathrm{Co}_{2}}=\mathbf{0 . 8 0 2 9}$} \\
\hline \multicolumn{3}{|c|}{$T=263.15 \pm 0.05 \mathrm{~K}$} & \multicolumn{3}{|c|}{$T=273.15 \pm 0.05 \mathrm{~K}$} & \multicolumn{3}{|c|}{$T=293.15 \pm 0.05 \mathrm{~K}$} & \multicolumn{3}{|c|}{$T=304.21 \pm 0.05 \mathrm{~K}$} \\
\hline $\begin{array}{c}p \\
(\mathbf{M P a})\end{array}$ & $\begin{array}{c}\rho \\
\left(\mathbf{k g} \cdot \mathbf{m}^{-3}\right)\end{array}$ & $\begin{array}{c}\boldsymbol{u}_{\rho} \\
\left(\mathbf{k g} \cdot \mathbf{m}^{-3}\right)\end{array}$ & $\begin{array}{c}\boldsymbol{p} \\
(\mathbf{M P a})\end{array}$ & $\begin{array}{c}\rho \\
\left(\mathbf{k g} \cdot \mathbf{m}^{-3}\right)\end{array}$ & $\begin{array}{c}u_{\rho} \\
\left(\mathbf{k g} \cdot \mathbf{m}^{-3}\right)\end{array}$ & $\begin{array}{c}p \\
(\mathbf{M P a})\end{array}$ & $\begin{array}{c}\rho \\
\left(\mathbf{k g} \cdot \mathbf{m}^{-3}\right)\end{array}$ & $\begin{array}{c}\boldsymbol{u}_{\rho} \\
\left(\mathbf{k g} \cdot \mathbf{m}^{-3}\right)\end{array}$ & $\begin{array}{c}\boldsymbol{p} \\
(\mathbf{M P a})\end{array}$ & $\begin{array}{c}\rho \\
\left(\mathbf{k g} \cdot \mathbf{m}^{-3}\right)\end{array}$ & $\begin{array}{c}u_{\rho} \\
\left(\mathbf{k g} \cdot \mathbf{m}^{-3}\right)\end{array}$ \\
\hline 0.100 & 2.50 & 0.24 & 0.100 & 1,5 & 0.23 & 0.100 & 2.11 & 0.24 & 0.100 & 1.86 & 0.23 \\
\hline 0.156 & 3.82 & 0.24 & 0.182 & 4.03 & 0.23 & 0.230 & 4.68 & 0.24 & 0.277 & 5.16 & 0.23 \\
\hline 0.212 & 5.10 & 0.23 & 0.263 & 5.86 & 0.23 & 0.361 & 7.36 & 0.24 & 0.454 & 8.65 & 0.23 \\
\hline 0.268 & 6.36 & 0.23 & 0.345 & 7.65 & 0.23 & 0.491 & 10.06 & 0.24 & 0.630 & 12.21 & 0.23 \\
\hline 0.323 & 7.62 & 0.23 & 0.427 & 9.49 & 0.23 & 0.621 & 12.82 & 0.24 & 0.807 & 15.91 & 0.23 \\
\hline 0.379 & 8.98 & 0.23 & 0.508 & 11.34 & 0.23 & 0.751 & 15.60 & 0.24 & 0.984 & 19.63 & 0.23 \\
\hline 0.435 & 10.40 & 0.23 & 0.590 & 13.26 & 0.23 & 0.882 & 18.54 & 0.24 & 1.161 & 23.40 & 0.23 \\
\hline 0.491 & 11.72 & 0.23 & 0.672 & 15.21 & 0.23 & 1.012 & 21.48 & 0.24 & 1.338 & 27.40 & 0.24 \\
\hline 2.134 & 1101.18 & 0.61 & 0.767 & 17.46 & 0.22 & 1.142 & 24.45 & 0.24 & 1.515 & 31.45 & 0.24 \\
\hline 2.569 & 1102.93 & 0.61 & 3.013 & 1059.70 & 0.59 & 1.273 & 27.55 & 0.24 & 1.691 & 35.59 & 0.24 \\
\hline 3.005 & 1104.57 & 0.61 & 3.447 & 1061.84 & 0.59 & 1.403 & 30.81 & 0.24 & 1.868 & 39.83 & 0.24 \\
\hline 3.441 & 1106.25 & 0.61 & 3.881 & 1064.00 & 0.59 & 1.631 & 36.49 & 0.24 & 2.045 & 44.26 & 0.24 \\
\hline 3.877 & 1107.88 & 0.61 & 4.315 & 1066.17 & 0.59 & 4.395 & 972.88 & 1.87 & 2.222 & 48.77 & 0.24 \\
\hline 4.312 & 1109.54 & 0.61 & 4.750 & 1068.26 & 0.59 & 4.821 & 977.32 & 1.64 & 2.318 & 51.29 & 0.24 \\
\hline 4.748 & 1111.09 & 0.61 & 5.184 & 1070.33 & 0.59 & 5.247 & 981.38 & 1.41 & 2.415 & 53.90 & 0.24 \\
\hline 5.184 & 1112.65 & 0.61 & 5.618 & 1072.34 & 0.60 & 5.673 & 985.19 & 1.19 & 5.633 & 887.53 & 1.26 \\
\hline 5.620 & 1114.19 & 0.61 & 6.052 & 1074.27 & 0.60 & 6.100 & 988.77 & 0.56 & 6.061 & 894.39 & 1.11 \\
\hline 6.056 & 1115.76 & 0.61 & 6.486 & 1076.22 & 0.60 & 6.526 & 992.35 & 0.56 & 6.490 & 900.35 & 0.96 \\
\hline 6.491 & 1117.22 & 0.62 & 6.920 & 1078.10 & 0.60 & 6.952 & 995.71 & 0.56 & 6.918 & 905.87 & 0.81 \\
\hline 6.927 & 1118.73 & 0.62 & 7.355 & 1079.86 & 0.60 & 7.378 & 998.97 & 0.56 & 7.347 & 910.89 & 0.70 \\
\hline 7.363 & 1120.17 & 0.62 & 7.789 & 1081.60 & 0.60 & 7.804 & 1002.02 & 0.57 & 7.776 & 915.43 & 0.54 \\
\hline 7.799 & 1121.50 & 0.62 & 8.223 & 1083.40 & 0.60 & 8.231 & 1005.04 & 0.57 & 8.204 & 919.65 & 0.54 \\
\hline 8.234 & 1122.94 & 0.62 & 8.657 & 1085.12 & 0.60 & 8.657 & 1008.18 & 0.57 & 8.633 & 924.05 & 0.54 \\
\hline 8.670 & 1124.39 & 0.62 & 9.091 & 1086.86 & 0.60 & 9.083 & 1011.20 & 0.57 & 9.062 & 928.35 & 0.54 \\
\hline 9.106 & 1125.82 & 0.62 & 9.526 & 1088.54 & 0.60 & 9.509 & 1014.01 & 0.57 & 9.490 & 932.35 & 0.54 \\
\hline 9.542 & 1127.20 & 0.62 & 9.960 & 1090.18 & 0.60 & 9.935 & 1016.82 & 0.57 & 9.919 & 936.18 & 0.54 \\
\hline 9.977 & 1128.49 & 0.62 & 10.394 & 1091.88 & 0.60 & 10.362 & 1019.53 & 0.57 & 10.347 & 939.99 & 0.54 \\
\hline 10.413 & 1129.84 & 0.62 & 10.828 & 1093.60 & 0.60 & 10.788 & 1022.19 & 0.57 & 10.776 & 943.71 & 0.54 \\
\hline 10.849 & 1131.15 & 0.62 & 11.262 & 1095.26 & 0.60 & 11.214 & 1024.93 & 0.57 & 11.205 & 947.23 & 0.54 \\
\hline 11.285 & 1132.49 & 0.62 & 11.696 & 1096.90 & 0.61 & 11.640 & 1027.52 & 0.57 & 11.633 & 950.60 & 0.54 \\
\hline 11.720 & 1133.79 & 0.62 & 12.131 & 1098.48 & 0.61 & 12.066 & 1030.04 & 0.58 & 12.062 & 953.80 & 0.54 \\
\hline 12.156 & 1135.07 & 0.62 & 12.565 & 1100.07 & 0.61 & 12.492 & 1032.51 & 0.58 & 12.491 & 956.99 & 0.54 \\
\hline 12.592 & 1136.38 & 0.62 & 12.999 & 1101.63 & 0.61 & 12.919 & 1034.95 & 0.58 & 12.919 & 960.09 & 0.54 \\
\hline 13.028 & 1137.61 & 0.62 & 13.433 & 1103.14 & 0.61 & 13.345 & 1037.33 & 0.58 & 13.348 & 963.01 & 0.54 \\
\hline 13.464 & 1138.86 & 0.62 & 13.849 & 1104.58 & 0.61 & 13.771 & 1039.62 & 0.58 & 13.776 & 965.95 & 0.55 \\
\hline 13.899 & 1140.11 & 0.62 & 14.283 & 1106.08 & 0.61 & 14.197 & 1041.96 & 0.58 & 14.205 & 968.75 & 0.55 \\
\hline 14.335 & 1141.34 & 0.63 & 14.718 & 1107.50 & 0.61 & 14.623 & 1044.12 & 0.58 & 14.634 & 971.51 & 0.55 \\
\hline 14.771 & 1142.57 & 0.63 & 15.152 & 1108.98 & 0.61 & 15.050 & 1046.30 & 0.58 & 15.062 & 974.25 & 0.55 \\
\hline 15.207 & 1143.78 & 0.63 & 15.586 & 1110.36 & 0.61 & 15.476 & 1048.45 & 0.58 & 15.491 & 976.86 & 0.55 \\
\hline 15.642 & 1145.02 & 0.63 & 16.020 & 1111.82 & 0.61 & 15.902 & 1050.58 & 0.58 & 15.920 & 979.48 & 0.55 \\
\hline 16.078 & 1146.19 & 0.63 & 16.454 & 1113.20 & 0.61 & 16.328 & 1052.69 & 0.58 & 16.348 & 981.95 & 0.55 \\
\hline 16.514 & 1147.40 & 0.63 & 16.888 & 1114.58 & 0.61 & 16.754 & 1054.71 & 0.59 & 16.777 & 984.48 & 0.55 \\
\hline
\end{tabular}




\begin{tabular}{llllllllllll}
16.950 & 1148.56 & 0.63 & 17.323 & 1115.95 & 0.61 & 17.181 & 1056.74 & 0.59 & 17.205 & 986.90 & 0.55 \\
17.385 & 1149.69 & 0.63 & 17.757 & 1117.36 & 0.61 & 17.607 & 1058.72 & 0.59 & 17.634 & 989.33 & 0.55 \\
17.821 & 1150.85 & 0.63 & 18.191 & 1118.72 & 0.62 & 18.033 & 1060.64 & 0.59 & 18.063 & 991.67 & 0.56 \\
18.257 & 1152.01 & 0.63 & 18.625 & 1120.07 & 0.62 & 18.459 & 1062.54 & 0.59 & 18.491 & 993.94 & 0.56 \\
18.693 & 1153.10 & 0.63 & 19.059 & 1121.36 & 0.62 & 18.885 & 1064.39 & 0.59 & 18.920 & 996.22 & 0.56 \\
19.128 & 1154.25 & 0.63 & 19.493 & 1122.69 & 0.62 & 19.312 & 1066.20 & 0.59 & 19.348 & 998.52 & 0.56 \\
19.564 & 1155.32 & 0.63 & 19.928 & 1123.99 & 0.62 & 19.738 & 1068.04 & 0.59 & 19.777 & 1000.79 & 0.56 \\
20.000 & 1156.42 & 0.63 & 20.000 & 1124.19 & 0.62 & 20.000 & 1069.11 & 0.59 & 20.000 & 1001.87 & 0.56 \\
\hline
\end{tabular}

Table 1 (continued). $p \rho T x_{\mathrm{CO}_{2}}$ experimental data for the $\mathrm{CO}_{2}+\mathrm{SO}_{2}$ mixtures. $u_{\rho}$ : combined uncertainty.

\begin{tabular}{|c|c|c|c|c|c|c|c|c|c|c|c|}
\hline \multicolumn{12}{|c|}{$x_{\mathrm{CO}_{2}}=0.8969$} \\
\hline \multicolumn{3}{|c|}{$T=263.15 \pm 0.05 \mathrm{~K}$} & \multicolumn{3}{|c|}{$T=273.15 \pm 0.05 \mathrm{~K}$} & \multicolumn{3}{|c|}{$T=293.15 \pm 0.05 \mathrm{~K}$} & \multicolumn{3}{|c|}{$T=304.21 \pm 0.05 \mathrm{~K}$} \\
\hline $\begin{array}{c}p \\
(\mathbf{M P a})\end{array}$ & $\begin{array}{c}\rho \\
\left(\mathbf{k g} \cdot \mathbf{m}^{-3}\right) \\
\end{array}$ & $\begin{array}{c}\boldsymbol{u}_{\rho} \\
\left(\mathbf{k g} \cdot \mathbf{m}^{-3}\right)\end{array}$ & $\begin{array}{c}\boldsymbol{p} \\
(\mathbf{M P a})\end{array}$ & $\begin{array}{c}\rho \\
\left(\mathbf{k g} \cdot \mathbf{m}^{-3}\right) \\
\end{array}$ & $\begin{array}{c}u_{\rho} \\
\left(\mathbf{k g} \cdot \mathbf{m}^{-3}\right)\end{array}$ & $\begin{array}{c}\boldsymbol{p} \\
(\mathbf{M P a})\end{array}$ & $\begin{array}{c}\rho \\
\left(\mathbf{k g} \cdot \mathbf{m}^{-3}\right) \\
\end{array}$ & $\begin{array}{c}u_{\rho} \\
\left(\mathbf{k g} \cdot \mathbf{m}^{-3}\right)\end{array}$ & $\begin{array}{c}\boldsymbol{p} \\
(\mathbf{M P a})\end{array}$ & $\begin{array}{c}\rho \\
\left(\mathbf{k g} \cdot \mathbf{m}^{-3}\right) \\
\end{array}$ & $\begin{array}{c}u_{\rho} \\
\left(\mathrm{kg} \cdot \mathbf{m}^{-3}\right)\end{array}$ \\
\hline 0.100 & 2.43 & 0.24 & 0.107 & 2.37 & 0.23 & 0.100 & 1.89 & 0.23 & 0.100 & 1.95 & 0.24 \\
\hline 0.214 & 4.95 & 0.23 & 0.239 & 5.14 & 0.23 & 0.362 & 7.22 & 0.23 & 0.394 & 7.61 & 0.23 \\
\hline 0.328 & 7.49 & 0.23 & 0.371 & 7.91 & 0.23 & 0.624 & 12.67 & 0.23 & 0.687 & 13.34 & 0.23 \\
\hline 0.442 & 10.16 & 0.23 & 0.489 & 10.44 & 0.23 & 0.886 & 18.20 & 0.23 & 0.981 & 19.41 & 0.23 \\
\hline 0.557 & 12.84 & 0.23 & 0.655 & 14.08 & 0.23 & 1.148 & 23.73 & 0.23 & 1.274 & 25.73 & 0.23 \\
\hline 0.671 & 15.59 & 0.23 & 0.796 & 17.24 & 0.23 & 1.410 & 29.66 & 0.23 & 1.568 & 32.29 & 0.24 \\
\hline 0.785 & 18.38 & 0.23 & 0.919 & 20.09 & 0.23 & 1.671 & 35.81 & 0.23 & 1.861 & 39.21 & 0.24 \\
\hline 0.866 & 20.67 & 0.23 & 1.115 & 24.84 & 0.23 & 1.933 & 42.18 & 0.23 & 2.155 & 46.53 & 0.24 \\
\hline 2.512 & 1057.15 & 0.58 & 1.293 & 29.12 & 0.23 & 2.195 & 48.75 & 0.23 & 2.449 & 54.23 & 0.24 \\
\hline 2.954 & 1059.28 & 0.59 & 3.319 & 1005.14 & 0.56 & 2.457 & 55.53 & 0.23 & 2.742 & 62.22 & 0.24 \\
\hline 3.397 & 1061.16 & 0.59 & 3.748 & 1008.36 & 0.56 & 2.719 & 62.75 & 0.23 & 3.036 & 70.27 & 0.24 \\
\hline 3.839 & 1063.04 & 0.59 & 4.182 & 1011.18 & 0.56 & 2.865 & 66.92 & 0.23 & 3.329 & 78.32 & 0.24 \\
\hline 4.281 & 1064.84 & 0.59 & 4.616 & 1013.84 & 0.56 & 5.107 & 895.64 & 1.30 & 3.623 & 86.69 & 0.24 \\
\hline 4.723 & 1066.66 & 0.59 & 5.050 & 1016.54 & 0.57 & 5.514 & 900.68 & 1.16 & 3.917 & 95.47 & 0.24 \\
\hline 5.166 & 1068.48 & 0.59 & 5.483 & 1019.06 & 0.57 & 5.929 & 906.25 & 0.52 & 4.126 & 102.16 & 0.24 \\
\hline 5.608 & 1070.15 & 0.59 & 5.917 & 1021.49 & 0.57 & 6.343 & 911.11 & 0.52 & 6.199 & 795.76 & 0.93 \\
\hline 6.050 & 1071.83 & 0.59 & 6.351 & 1023.94 & 0.57 & 6.741 & 915.24 & 0.52 & 6.617 & 808.73 & 0.88 \\
\hline 6.492 & 1073.53 & 0.59 & 6.785 & 1026.36 & 0.57 & 7.155 & 919.56 & 0.52 & 7.035 & 819.52 & 0.76 \\
\hline 6.935 & 1075.13 & 0.59 & 7.219 & 1028.71 & 0.57 & 7.570 & 923.61 & 0.52 & 7.454 & 829.05 & 0.50 \\
\hline 7.377 & 1076.72 & 0.59 & 7.653 & 1031.11 & 0.57 & 7.984 & 927.48 & 0.53 & 7.872 & 837.18 & 0.50 \\
\hline 7.819 & 1078.39 & 0.59 & 8.087 & 1033.33 & 0.57 & 8.398 & 931.33 & 0.53 & 8.290 & 844.72 & 0.50 \\
\hline 8.261 & 1079.94 & 0.59 & 8.521 & 1035.52 & 0.57 & 8.813 & 934.97 & 0.53 & 8.708 & 851.59 & 0.50 \\
\hline 8.704 & 1081.51 & 0.60 & 8.954 & 1037.69 & 0.58 & 9.227 & 938.50 & 0.53 & 9.126 & 858.03 & 0.50 \\
\hline 9.146 & 1083.04 & 0.60 & 9.388 & 1039.81 & 0.58 & 9.641 & 941.91 & 0.53 & 9.545 & 863.92 & 0.50 \\
\hline 9.588 & 1084.49 & 0.60 & 9.822 & 1041.84 & 0.58 & 10.056 & 945.29 & 0.53 & 9.963 & 869.50 & 0.50 \\
\hline 10.031 & 1085.99 & 0.60 & 10.256 & 1043.86 & 0.58 & 10.470 & 948.52 & 0.53 & 10.381 & 874.78 & 0.50 \\
\hline 10.473 & 1087.44 & 0.60 & 10.690 & 1045.82 & 0.58 & 10.884 & 951.56 & 0.54 & 10.799 & 879.77 & 0.51 \\
\hline 10.915 & 1088.90 & 0.60 & 11.124 & 1047.82 & 0.58 & 11.299 & 954.42 & 0.54 & 11.218 & 884.47 & 0.51 \\
\hline 11.357 & 1090.33 & 0.60 & 11.558 & 1049.79 & 0.58 & 11.713 & 957.27 & 0.54 & 11.636 & 888.93 & 0.51 \\
\hline 11.800 & 1091.75 & 0.60 & 11.991 & 1051.68 & 0.58 & 12.127 & 960.07 & 0.54 & 12.054 & 893.21 & 0.51 \\
\hline 12.242 & 1093.18 & 0.60 & 12.425 & 1053.63 & 0.58 & 12.542 & 962.78 & 0.54 & 12.472 & 897.43 & 0.51 \\
\hline 12.684 & 1094.58 & 0.60 & 12.859 & 1055.44 & 0.58 & 12.956 & 965.47 & 0.54 & 12.890 & 901.43 & 0.51 \\
\hline 13.126 & 1095.90 & 0.60 & 13.293 & 1057.17 & 0.58 & 13.370 & 968.14 & 0.54 & 13.309 & 905.29 & 0.51 \\
\hline 13.569 & 1097.27 & 0.60 & 13.727 & 1058.97 & 0.58 & 13.785 & 970.76 & 0.54 & 13.727 & 909.03 & 0.52 \\
\hline
\end{tabular}




\begin{tabular}{llllllllllll}
14.011 & 1098.54 & 0.60 & 14.161 & 1060.71 & 0.59 & 14.199 & 973.33 & 0.54 & 14.145 & 912.64 & 0.52 \\
14.453 & 1099.88 & 0.60 & 14.595 & 1062.50 & 0.59 & 14.613 & 975.86 & 0.55 & 14.563 & 916.07 & 0.52 \\
14.895 & 1101.16 & 0.60 & 15.029 & 1064.23 & 0.59 & 15.028 & 978.30 & 0.55 & 14.981 & 919.39 & 0.52 \\
15.338 & 1102.49 & 0.60 & 15.462 & 1065.98 & 0.59 & 15.442 & 980.70 & 0.55 & 15.400 & 922.65 & 0.52 \\
15.780 & 1103.73 & 0.61 & 15.896 & 1067.65 & 0.59 & 15.857 & 983.01 & 0.55 & 15.818 & 925.86 & 0.52 \\
16.222 & 1105.05 & 0.61 & 16.330 & 1069.37 & 0.59 & 16.271 & 985.34 & 0.55 & 16.236 & 928.98 & 0.52 \\
16.665 & 1106.33 & 0.61 & 16.764 & 1071.00 & 0.59 & 16.685 & 987.52 & 0.55 & 16.654 & 931.99 & 0.53 \\
17.107 & 1107.47 & 0.61 & 17.198 & 1072.70 & 0.59 & 17.100 & 989.59 & 0.55 & 17.073 & 934.97 & 0.53 \\
17.549 & 1108.71 & 0.61 & 17.632 & 1074.27 & 0.59 & 17.514 & 991.77 & 0.55 & 17.491 & 937.86 & 0.53 \\
17.991 & 1109.94 & 0.61 & 18.066 & 1075.88 & 0.59 & 17.928 & 993.86 & 0.55 & 17.909 & 940.68 & 0.53 \\
18.434 & 111.09 & 0.61 & 18.500 & 1077.45 & 0.59 & 18.343 & 995.82 & 0.55 & 18.327 & 943.38 & 0.53 \\
18.876 & 1112.25 & 0.61 & 18.933 & 1078.95 & 0.59 & 18.757 & 997.95 & 0.55 & 18.745 & 946.05 & 0.53 \\
19.318 & 1113.38 & 0.61 & 19.367 & 1080.49 & 0.59 & 19.171 & 999.97 & 0.56 & 19.164 & 948.69 & 0.53 \\
19.760 & 1114.51 & 0.61 & 19.801 & 1081.96 & 0.59 & 19.586 & 1001.95 & 0.56 & 19.582 & 951.15 & 0.53 \\
19.871 & 1114.83 & 0.61 & 19.928 & 1082.39 & 0.59 & 19.785 & 1002.93 & 0.56 & 19.808 & 952.43 & 0.53 \\
20.000 & 1115.11 & 0.61 & 20.000 & 1082.61 & 0.59 & 20.000 & 1003.92 & 0.56 & 20.000 & 953.37 & 0.53 \\
\hline
\end{tabular}

Table 1 (continued). $p \rho T x_{\mathrm{CO}_{2}}$ experimental data for the $\mathrm{CO}_{2}+\mathrm{SO}_{2}$ mixtures. $u_{\rho}$ : combined uncertainty.

\begin{tabular}{|c|c|c|c|c|c|c|c|c|c|c|c|}
\hline \multicolumn{12}{|c|}{$x_{\mathrm{Co}_{2}}=0.9532$} \\
\hline \multicolumn{3}{|c|}{$T=263.15 \pm 0.05 \mathrm{~K}$} & \multicolumn{3}{|c|}{$T=273.15 \pm 0.05 \mathrm{~K}$} & \multicolumn{3}{|c|}{$T=293.15 \pm 0.05 \mathrm{~K}$} & \multicolumn{3}{|c|}{$T=304.21 \pm 0.05 \mathrm{~K}$} \\
\hline $\begin{array}{c}p \\
(\mathbf{M P a}) \\
\end{array}$ & $\begin{array}{c}\boldsymbol{\rho} \\
\left(\mathbf{k g} \cdot \mathbf{m}^{-3}\right) \\
\end{array}$ & $\begin{array}{c}u_{\rho} \\
\left(\mathbf{k g} \cdot \mathbf{m}^{-3}\right)\end{array}$ & $\begin{array}{c}p \\
(\mathbf{M P a}) \\
\end{array}$ & $\begin{array}{c}\rho \rho \\
\left(\mathbf{k g} \cdot \mathbf{m}^{-3}\right) \\
\end{array}$ & $\begin{array}{c}u_{\rho} \\
\left(\mathbf{k g} \cdot \mathbf{m}^{-3}\right)\end{array}$ & $\begin{array}{c}p \\
(\mathbf{M P a}) \\
\end{array}$ & $\begin{array}{c}\boldsymbol{\rho} \\
\left(\mathbf{k g} \cdot \mathbf{m}^{-3}\right) \\
\end{array}$ & $\begin{array}{c}u_{\rho} \\
\left(\mathbf{k g} \cdot \mathbf{m}^{-3}\right)\end{array}$ & $\begin{array}{c}p \\
(\mathbf{M P a}) \\
\end{array}$ & $\begin{array}{c}\rho \\
\left(\mathbf{k g} \cdot \mathbf{m}^{-3}\right) \\
\end{array}$ & $\begin{array}{c}u_{\rho} \\
\left(\mathbf{k g} \cdot \mathbf{m}^{-3}\right)\end{array}$ \\
\hline 0.100 & 2.43 & 0.25 & 0.100 & 2.27 & 0.24 & 0.100 & 2.01 & 0.24 & 0.100 & 1.80 & 0.23 \\
\hline 0.300 & 6.69 & 0.23 & 0.358 & 7.55 & 0.23 & 0.501 & 9.78 & 0.24 & 0.512 & 9.49 & 0.23 \\
\hline 0.499 & 11.10 & 0.23 & 0.616 & 13.05 & 0.23 & 0.881 & 17.45 & 0.24 & 0.924 & 17.34 & 0.23 \\
\hline 0.699 & 15.67 & 0.23 & 0.897 & 19.30 & 0.23 & 1.261 & 25.57 & 0.23 & 1.336 & 25.76 & 0.23 \\
\hline 0.898 & 20.55 & 0.23 & 1.178 & 25.89 & 0.23 & 1.641 & 34.03 & 0.24 & 1.747 & 34.69 & 0.23 \\
\hline 1.098 & 25.52 & 0.23 & 1.436 & 32.24 & 0.23 & 2.021 & 43.02 & 0.23 & 2.159 & 44.06 & 0.23 \\
\hline 1.328 & 31.57 & 0.23 & 1.694 & 38.92 & 0.23 & 2.401 & 52.62 & 0.23 & 2.571 & 53.90 & 0.23 \\
\hline 1.559 & 38.28 & 0.23 & 1.952 & 45.98 & 0.23 & 2.780 & 62.90 & 0.23 & 2.983 & 64.18 & 0.23 \\
\hline 2.718 & 1018.24 & 0.39 & 2.280 & 55.72 & 0.23 & 3.160 & 74.19 & 0.23 & 3.395 & 75.40 & 0.23 \\
\hline 3.142 & 1020.89 & 0.39 & 3.620 & 968.41 & 0.38 & 3.540 & 86.56 & 0.23 & 3.807 & 87.54 & 0.23 \\
\hline 3.586 & 1023.20 & 0.39 & 4.042 & 971.45 & 0.38 & 3.920 & 100.50 & 0.23 & 4.218 & 100.94 & 0.24 \\
\hline 4.010 & 1025.43 & 0.39 & 4.464 & 974.26 & 0.38 & 4.300 & 116.65 & 0.23 & 4.630 & 116.02 & 0.24 \\
\hline 4.454 & 1027.67 & 0.39 & 4.886 & 977.42 & 0.38 & 5.330 & 828.42 & 1.09 & 5.042 & 133.28 & 0.24 \\
\hline 4.878 & 1029.71 & 0.39 & 5.308 & 980.07 & 0.38 & 5.731 & 837.31 & 0.35 & 5.454 & 153.59 & 0.25 \\
\hline 5.322 & 1031.78 & 0.39 & 5.729 & 982.81 & 0.38 & 6.134 & 844.79 & 0.35 & 5.895 & 181.21 & 0.26 \\
\hline 5.746 & 1033.79 & 0.39 & 6.133 & 985.40 & 0.38 & 6.537 & 851.68 & 0.35 & 6.748 & 722.45 & 0.68 \\
\hline 6.190 & 1035.75 & 0.39 & 6.537 & 987.87 & 0.38 & 6.940 & 857.73 & 0.35 & 7.146 & 744.47 & 0.58 \\
\hline 6.614 & 1037.67 & 0.39 & 6.958 & 990.41 & 0.38 & 7.343 & 863.48 & 0.35 & 7.545 & 760.68 & 0.46 \\
\hline 7.058 & 1039.63 & 0.39 & 7.380 & 992.83 & 0.38 & 7.746 & 868.95 & 0.35 & 7.943 & 772.96 & 0.46 \\
\hline 7.482 & 1041.51 & 0.39 & 7.802 & 995.27 & 0.38 & 8.149 & 874.06 & 0.35 & 8.342 & 784.45 & 0.46 \\
\hline 7.926 & 1043.40 & 0.39 & 8.224 & 997.59 & 0.38 & 8.552 & 878.82 & 0.36 & 8.740 & 794.48 & 0.47 \\
\hline 8.350 & 1045.22 & 0.39 & 8.646 & 999.87 & 0.38 & 8.955 & 883.43 & 0.36 & 9.139 & 803.35 & 0.47 \\
\hline 8.794 & 1047.08 & 0.39 & 9.068 & 1002.07 & 0.38 & 9.358 & 887.75 & 0.36 & 9.538 & 811.29 & 0.47 \\
\hline 9.218 & 1048.79 & 0.40 & 9.490 & 1004.27 & 0.38 & 9.761 & 891.86 & 0.36 & 9.936 & 818.56 & 0.48 \\
\hline 9.662 & 1050.58 & 0.40 & 9.912 & 1006.45 & 0.39 & 10.164 & 895.73 & 0.36 & 10.335 & 825.37 & 0.48 \\
\hline 10.105 & 1052.35 & 0.40 & 10.333 & 1008.50 & 0.39 & 10.567 & 899.57 & 0.36 & 10.733 & 831.77 & 0.48 \\
\hline
\end{tabular}




\begin{tabular}{llllllllllll}
10.530 & 1054.02 & 0.40 & 10.755 & 1010.62 & 0.39 & 10.970 & 903.27 & 0.36 & 11.132 & 837.66 & 0.48 \\
10.973 & 1055.73 & 0.40 & 11.177 & 1012.66 & 0.39 & 11.373 & 906.90 & 0.36 & 11.530 & 843.35 & 0.49 \\
11.398 & 1057.36 & 0.40 & 11.599 & 1014.64 & 0.39 & 11.776 & 910.39 & 0.36 & 11.929 & 848.64 & 0.49 \\
11.841 & 1059.03 & 0.40 & 12.021 & 1016.62 & 0.39 & 12.179 & 913.70 & 0.36 & 12.311 & 853.52 & 0.49 \\
12.285 & 1060.68 & 0.40 & 12.443 & 1018.59 & 0.39 & 12.582 & 916.99 & 0.36 & 12.710 & 858.34 & 0.49 \\
12.709 & 1062.24 & 0.40 & 12.846 & 1020.39 & 0.39 & 12.985 & 920.11 & 0.36 & 13.108 & 863.01 & 0.49 \\
13.153 & 1063.81 & 0.40 & 13.268 & 1022.23 & 0.39 & 13.388 & 923.19 & 0.36 & 13.507 & 867.42 & 0.50 \\
13.577 & 1065.40 & 0.40 & 13.690 & 1024.09 & 0.39 & 13.791 & 926.19 & 0.37 & 13.905 & 871.71 & 0.50 \\
14.021 & 1066.97 & 0.40 & 14.112 & 1025.91 & 0.39 & 14.194 & 929.13 & 0.37 & 14.304 & 875.78 & 0.50 \\
14.445 & 1068.49 & 0.40 & 14.516 & 1027.65 & 0.39 & 14.597 & 932.06 & 0.37 & 14.702 & 879.77 & 0.50 \\
14.889 & 1070.03 & 0.40 & 14.937 & 1029.39 & 0.39 & 15.000 & 934.91 & 0.37 & 15.101 & 883.54 & 0.50 \\
15.332 & 1071.58 & 0.40 & 15.359 & 1031.10 & 0.39 & 15.403 & 937.58 & 0.37 & 15.500 & 887.27 & 0.50 \\
15.757 & 1072.96 & 0.40 & 15.781 & 1032.81 & 0.39 & 15.806 & 940.29 & 0.37 & 15.898 & 890.86 & 0.51 \\
16.200 & 1074.52 & 0.40 & 16.203 & 1034.52 & 0.39 & 16.208 & 942.90 & 0.37 & 16.297 & 894.36 & 0.51 \\
16.625 & 1075.88 & 0.40 & 16.625 & 1036.19 & 0.39 & 16.611 & 945.47 & 0.37 & 16.695 & 897.70 & 0.51 \\
17.068 & 1077.36 & 0.40 & 17.047 & 1037.84 & 0.39 & 16.996 & 947.88 & 0.37 & 17.094 & 900.90 & 0.51 \\
17.512 & 1078.79 & 0.40 & 17.469 & 1039.49 & 0.39 & 17.399 & 950.24 & 0.37 & 17.492 & 904.06 & 0.51 \\
17.936 & 1080.17 & 0.40 & 17.891 & 1041.08 & 0.39 & 17.802 & 952.71 & 0.37 & 17.891 & 907.13 & 0.51 \\
18.303 & 1081.29 & 0.40 & 18.312 & 1042.66 & 0.39 & 18.205 & 955.03 & 0.37 & 18.289 & 910.09 & 0.51 \\
18.843 & 1082.95 & 0.40 & 18.808 & 1044.53 & 0.39 & 18.608 & 957.33 & 0.37 & 18.688 & 912.96 & 0.51 \\
19.190 & 1083.98 & 0.40 & 19.120 & 1045.65 & 0.39 & 19.011 & 959.56 & 0.37 & 19.087 & 915.88 & 0.52 \\
19.441 & 1084.73 & 0.40 & 19.395 & 1046.63 & 0.39 & 19.304 & 961.14 & 0.37 & 19.485 & 918.63 & 0.52 \\
19.730 & 1085.56 & 0.40 & 19.670 & 1047.58 & 0.39 & 19.707 & 963.33 & 0.37 & 19.768 & 920.49 & 0.52 \\
20.000 & 1086.34 & 0.40 & 20.000 & 1048.75 & 0.39 & 20.000 & 964.83 & 0.37 & 20.000 & 922.01 & 0.52 \\
\hline
\end{tabular}

Table 1 (continued). $p \rho T x_{\mathrm{CO}_{2}}$ experimental data for the $\mathrm{CO}_{2}+\mathrm{SO}_{2}$ mixtures. $u_{\rho}$ : combined uncertainty.

\begin{tabular}{|c|c|c|c|c|c|c|c|c|c|c|c|}
\hline \multicolumn{12}{|c|}{$x_{\mathrm{CO}_{2}}=0.9698$} \\
\hline \multicolumn{3}{|c|}{$T=263.15 \pm 0.05 \mathrm{~K}$} & \multicolumn{3}{|c|}{$T=273.15 \pm 0.05 \mathrm{~K}$} & \multicolumn{3}{|c|}{$T=293.15 \pm 0.05 \mathrm{~K}$} & \multicolumn{3}{|c|}{$T=304.21 \pm 0.05 \mathrm{~K}$} \\
\hline $\begin{array}{c}p \\
(\mathbf{M P a})\end{array}$ & $\begin{array}{c}\rho \\
\left(\mathbf{k g} \cdot \mathbf{m}^{-3}\right)\end{array}$ & $\begin{array}{c}\boldsymbol{u}_{\rho} \\
\left(\mathbf{k g} \cdot \mathbf{m}^{-3}\right)\end{array}$ & $\begin{array}{c}p \\
(\mathbf{M P a})\end{array}$ & $\begin{array}{c}\rho \\
\left(\mathbf{k g} \cdot \mathbf{m}^{-3}\right)\end{array}$ & $\begin{array}{c}\boldsymbol{u}_{\rho} \\
\left(\mathbf{k g} \cdot \mathbf{m}^{-3}\right)\end{array}$ & $\begin{array}{c}p \\
(\mathbf{M P a})\end{array}$ & $\begin{array}{c}\rho \\
\left(\mathbf{k g} \cdot \mathbf{m}^{-3}\right)\end{array}$ & $\begin{array}{c}u_{\rho} \\
\left(\mathbf{k g} \cdot \mathbf{m}^{-3}\right)\end{array}$ & $\begin{array}{c}\boldsymbol{p} \\
(\mathbf{M P a})\end{array}$ & $\begin{array}{c}\rho \\
\left(\mathbf{k g} \cdot \mathbf{m}^{-3}\right)\end{array}$ & $\underset{\left(\mathbf{k g} \cdot \mathbf{m}^{-3}\right)}{u_{\rho}}$ \\
\hline 0.100 & 2.43 & 0.25 & 0.100 & 2.11 & 0.23 & 0.100 & 2.16 & 0.25 & 0.100 & 1.99 & 0.24 \\
\hline 0.356 & 7.81 & 0.23 & 0.417 & 8.53 & 0.23 & 0.526 & 10.21 & 0.23 & 0.544 & 9.92 & 0.23 \\
\hline 0.612 & 13.48 & 0.23 & 0.733 & 15.27 & 0.23 & 0.952 & 19.04 & 0.23 & 0.989 & 18.41 & 0.23 \\
\hline 0.869 & 19.37 & 0.23 & 1.050 & 22.72 & 0.23 & 1.378 & 27.96 & 0.23 & 1.433 & 27.47 & 0.23 \\
\hline 1.125 & 25.59 & 0.23 & 1.366 & 30.02 & 0.23 & 1.803 & 37.58 & 0.23 & 1.877 & 36.97 & 0.23 \\
\hline 1.381 & 32.25 & 0.23 & 1.683 & 38.12 & 0.23 & 2.253 & 48.33 & 0.23 & 2.322 & 46.90 & 0.23 \\
\hline 1.617 & 38.86 & 0.23 & 2.000 & 46.78 & 0.23 & 2.702 & 60.00 & 0.23 & 2.766 & 57.54 & 0.23 \\
\hline 1.913 & 48.13 & 0.23 & 2.316 & 56.70 & 0.23 & 3.128 & 72.09 & 0.23 & 3.242 & 69.74 & 0.23 \\
\hline 2.701 & 1007.43 & 0.56 & 2.581 & 65.83 & 0.23 & 3.554 & 85.57 & 0.23 & 3.718 & 83.15 & 0.23 \\
\hline 3.125 & 1009.66 & 0.56 & 3.916 & 958.46 & 0.54 & 3.980 & 100.64 & 0.23 & 4.163 & 96.93 & 0.23 \\
\hline 3.549 & 1011.82 & 0.56 & 4.794 & 965.62 & 0.54 & 4.406 & 118.36 & 0.23 & 4.607 & 112.20 & 0.24 \\
\hline 3.973 & 1014.04 & 0.56 & 5.197 & 968.52 & 0.54 & 4.822 & 139.27 & 0.24 & 5.051 & 129.78 & 0.24 \\
\hline 4.396 & 1016.24 & 0.56 & 5.581 & 971.30 & 0.54 & 5.479 & 816.46 & 1.01 & 5.496 & 150.15 & 0.24 \\
\hline 4.820 & 1018.42 & 0.56 & 5.965 & 973.96 & 0.54 & 5.882 & 824.86 & 0.34 & 5.940 & 174.86 & 0.25 \\
\hline 5.244 & 1020.52 & 0.56 & 6.368 & 976.53 & 0.54 & 6.284 & 833.40 & 0.35 & 6.384 & 209.86 & 0.26 \\
\hline 5.668 & 1022.57 & 0.56 & 6.752 & 978.87 & 0.54 & 6.686 & 840.37 & 0.35 & 7.708 & 734.63 & 0.44 \\
\hline 6.092 & 1024.61 & 0.57 & 7.136 & 981.17 & 0.55 & 7.089 & 847.14 & 0.35 & 8.068 & 747.17 & 0.45 \\
\hline 6.515 & 1026.57 & 0.57 & 7.521 & 983.48 & 0.55 & 7.491 & 853.33 & 0.35 & 8.444 & 759.88 & 0.45 \\
\hline
\end{tabular}




\begin{tabular}{|c|c|c|c|c|c|c|c|c|c|c|c|}
\hline 6.939 & 1028.52 & 0.57 & 7.905 & 985.81 & 0.55 & 7.893 & 859.19 & 0.35 & 8.804 & 769.91 & 0.45 \\
\hline 7.363 & 1030.45 & 0.57 & 8.289 & 988.07 & 0.55 & 8.296 & 864.71 & 0.35 & 9.181 & 779.63 & 0.46 \\
\hline 7.787 & 1032.33 & 0.57 & 8.692 & 990.36 & 0.55 & 8.698 & 869.93 & 0.35 & 9.541 & 787.56 & 0.46 \\
\hline 8.191 & 1034.10 & 0.57 & 9.094 & 992.62 & 0.55 & 9.100 & 874.79 & 0.35 & 9.917 & 794.81 & 0.46 \\
\hline 8.615 & 1035.94 & 0.57 & 9.497 & 994.83 & 0.55 & 9.503 & 879.30 & 0.35 & 10.277 & 801.89 & 0.47 \\
\hline 9.039 & 1037.70 & 0.57 & 9.899 & 996.97 & 0.55 & 9.905 & 883.66 & 0.36 & 10.654 & 808.58 & 0.47 \\
\hline 9.463 & 1039.49 & 0.57 & 10.302 & 999.07 & 0.55 & 10.307 & 887.80 & 0.36 & 11.014 & 814.77 & 0.47 \\
\hline 9.887 & 1041.21 & 0.57 & 10.705 & 1001.08 & 0.55 & 10.710 & 891.81 & 0.36 & 11.390 & 820.60 & 0.47 \\
\hline 10.310 & 1042.94 & 0.57 & 11.107 & 1003.18 & 0.56 & 11.112 & 895.68 & 0.36 & 11.751 & 825.96 & 0.48 \\
\hline 10.734 & 1044.63 & 0.57 & 11.510 & 1005.15 & 0.56 & 11.514 & 899.41 & 0.36 & 12.127 & 831.10 & 0.48 \\
\hline 11.158 & 1046.27 & 0.57 & 11.912 & 1007.13 & 0.56 & 11.917 & 903.08 & 0.36 & 12.487 & 835.86 & 0.48 \\
\hline 11.582 & 1047.98 & 0.58 & 12.315 & 1009.07 & 0.56 & 12.319 & 906.61 & 0.36 & 12.864 & 840.64 & 0.48 \\
\hline 12.006 & 1049.56 & 0.58 & 12.717 & 1010.99 & 0.56 & 12.721 & 910.04 & 0.36 & 13.224 & 845.05 & 0.48 \\
\hline 12.429 & 1051.16 & 0.58 & 13.120 & 1012.94 & 0.56 & 13.124 & 913.41 & 0.36 & 13.600 & 849.33 & 0.49 \\
\hline 12.853 & 1052.79 & 0.58 & 13.522 & 1014.82 & 0.56 & 13.526 & 916.65 & 0.36 & 13.960 & 853.41 & 0.49 \\
\hline 13.277 & 1054.34 & 0.58 & 13.925 & 1016.59 & 0.56 & 13.928 & 919.83 & 0.36 & 14.337 & 857.52 & 0.49 \\
\hline 13.701 & 1055.89 & 0.58 & 14.328 & 1018.47 & 0.56 & 14.331 & 922.88 & 0.36 & 14.713 & 861.47 & 0.49 \\
\hline 14.125 & 1057.43 & 0.58 & 14.730 & 1020.20 & 0.56 & 14.733 & 925.87 & 0.36 & 15.073 & 865.14 & 0.49 \\
\hline 14.548 & 1058.92 & 0.58 & 15.133 & 1022.02 & 0.56 & 15.135 & 928.75 & 0.37 & 15.450 & 868.81 & 0.49 \\
\hline 14.972 & 1060.44 & 0.58 & 15.535 & 1023.67 & 0.57 & 15.538 & 931.58 & 0.37 & 15.810 & 872.24 & 0.50 \\
\hline 15.396 & 1062.00 & 0.58 & 15.938 & 1025.43 & 0.57 & 15.940 & 934.34 & 0.37 & 16.186 & 875.70 & 0.50 \\
\hline 15.820 & 1063.43 & 0.58 & 16.340 & 1027.07 & 0.57 & 16.342 & 936.95 & 0.37 & 16.546 & 878.89 & 0.50 \\
\hline 16.244 & 1064.87 & 0.58 & 16.743 & 1028.75 & 0.57 & 16.745 & 939.54 & 0.37 & 16.923 & 882.21 & 0.50 \\
\hline 16.667 & 1066.34 & 0.58 & 17.145 & 1030.36 & 0.57 & 17.147 & 942.02 & 0.37 & 17.283 & 885.25 & 0.50 \\
\hline 17.091 & 1067.71 & 0.58 & 17.548 & 1032.00 & 0.57 & 17.549 & 944.46 & 0.37 & 17.659 & 888.26 & 0.50 \\
\hline 17.515 & 1069.09 & 0.59 & 17.951 & 1033.61 & 0.57 & 17.952 & 946.80 & 0.37 & 18.019 & 891.19 & 0.50 \\
\hline 17.939 & 1070.48 & 0.59 & 18.353 & 1035.15 & 0.57 & 18.354 & 949.14 & 0.37 & 18.396 & 894.13 & 0.51 \\
\hline 18.363 & 1071.82 & 0.59 & 18.756 & 1036.68 & 0.57 & 18.756 & 951.35 & 0.37 & 18.756 & 896.76 & 0.51 \\
\hline 18.786 & 1073.17 & 0.59 & 19.103 & 1038.04 & 0.57 & 19.122 & 953.27 & 0.37 & 19.083 & 899.25 & 0.51 \\
\hline 19.210 & 1074.48 & 0.59 & 19.396 & 1039.14 & 0.57 & 19.433 & 954.94 & 0.37 & 19.427 & 901.72 & 0.51 \\
\hline 19.634 & 1075.81 & 0.59 & 19.744 & 1040.42 & 0.57 & 19.726 & 956.34 & 0.37 & 19.722 & 903.72 & 0.51 \\
\hline 20.000 & 1076.87 & 0.59 & 20.000 & 1041.34 & 0.57 & 20.000 & 957.70 & 0.37 & 20.000 & 905.60 & 0.51 \\
\hline
\end{tabular}

Table 1 (continued). $p \rho T x_{\mathrm{CO}_{2}}$ experimental data for the $\mathrm{CO}_{2}+\mathrm{SO}_{2}$ mixtures. $u_{\rho}$ : combined uncertainty.

\begin{tabular}{|c|c|c|c|c|c|c|c|c|c|c|c|}
\hline \multicolumn{12}{|c|}{$x_{\mathrm{CO}_{2}}=0.9931$} \\
\hline \multicolumn{3}{|c|}{$T=263.15 \pm 0.05 \mathrm{~K}$} & \multicolumn{3}{|c|}{$T=273.15 \pm 0.05 \mathrm{~K}$} & \multicolumn{3}{|c|}{$T=293.15 \pm 0.05 \mathrm{~K}$} & \multicolumn{3}{|c|}{$T=304.21 \pm 0.05 \mathrm{~K}$} \\
\hline $\begin{array}{c}\boldsymbol{p} \\
(\mathbf{M P a})\end{array}$ & $\begin{array}{c}\rho \\
\left(\mathbf{k g} \cdot \mathbf{m}^{-3}\right) \\
\end{array}$ & $\begin{array}{c}u_{\rho} \\
\left(\mathbf{k g} \cdot \mathbf{m}^{-3}\right)\end{array}$ & $\begin{array}{c}p \\
(\mathbf{M P a})\end{array}$ & $\begin{array}{c}\rho \\
\left(\mathbf{k g} \cdot \mathbf{m}^{-3}\right)\end{array}$ & $\begin{array}{c}u_{\rho} \\
\left(\mathbf{k g} \cdot \mathbf{m}^{-3}\right)\end{array}$ & $\begin{array}{c}\boldsymbol{p} \\
\text { (MPa) }\end{array}$ & $\begin{array}{c}\rho \\
\left(\mathbf{k g} \cdot \mathbf{m}^{-3}\right)\end{array}$ & $\begin{array}{c}u_{\rho} \\
\left(\mathbf{k g} \cdot \mathbf{m}^{-3}\right)\end{array}$ & $\begin{array}{c}\boldsymbol{p} \\
(\mathbf{M P a})\end{array}$ & $\begin{array}{c}\rho \\
\left(\mathbf{k g} \cdot \mathbf{m}^{-3}\right)\end{array}$ & $\begin{array}{c}u_{\rho} \\
\left(\mathbf{k g} \cdot \mathbf{m}^{-3}\right)\end{array}$ \\
\hline 0.100 & 2.41 & 0.25 & 0.100 & 1.95 & 0.22 & 0.100 & 1.81 & 0.22 & 0.100 & 1.72 & 0.22 \\
\hline 0.406 & 8.90 & 0.23 & 0.470 & 9.43 & 0.22 & 0.615 & 11.59 & 0.22 & 0.568 & 10.17 & 0.22 \\
\hline 0.712 & 15.68 & 0.23 & 0.861 & 17.83 & 0.22 & 1.130 & 21.86 & 0.22 & 1.035 & 19.06 & 0.22 \\
\hline 1.018 & 22.92 & 0.23 & 1.252 & 26.74 & 0.22 & 1.618 & 32.30 & 0.22 & 1.503 & 28.34 & 0.22 \\
\hline 1.324 & 30.58 & 0.23 & 1.622 & 35.81 & 0.23 & 2.106 & 43.71 & 0.23 & 1.971 & 38.23 & 0.23 \\
\hline 1.630 & 38.75 & 0.23 & 2.014 & 46.20 & 0.23 & 2.675 & 57.74 & 0.23 & 2.438 & 48.68 & 0.23 \\
\hline 1.936 & 47.65 & 0.23 & 2.405 & 57.67 & 0.23 & 3.136 & 70.56 & 0.23 & 2.906 & 59.79 & 0.23 \\
\hline 2.242 & 57.59 & 0.23 & 2.818 & 71.30 & 0.23 & 3.488 & 81.12 & 0.23 & 3.374 & 71.85 & 0.23 \\
\hline 2.788 & 988.48 & 0.55 & 3.290 & 89.81 & 0.23 & 3.895 & 94.56 & 0.23 & 3.841 & 84.86 & 0.23 \\
\hline 3.211 & 992.02 & 0.55 & 3.608 & 934.02 & 0.52 & 4.328 & 110.74 & 0.23 & 4.309 & 99.24 & 0.23 \\
\hline
\end{tabular}




\begin{tabular}{|c|c|c|c|c|c|c|c|c|c|c|c|}
\hline 3.634 & 994.55 & 0.55 & 4.015 & 937.75 & 0.52 & 4.898 & 136.45 & 0.24 & 4.777 & 115.18 & 0.23 \\
\hline 4.057 & 997.02 & 0.55 & 4.440 & 940.79 & 0.53 & 5.494 & 174.06 & 0.24 & 5.244 & 133.51 & 0.24 \\
\hline 4.480 & 999.40 & 0.55 & 4.866 & 944.42 & 0.53 & 5.726 & 787.14 & 0.91 & 5.712 & 154.91 & 0.24 \\
\hline 4.903 & 1001.66 & 0.55 & 5.292 & 947.74 & 0.53 & 6.120 & 796.99 & 0.46 & 6.290 & 188.48 & 0.25 \\
\hline 5.307 & 1003.80 & 0.55 & 5.718 & 950.87 & 0.53 & 6.514 & 806.65 & 0.47 & 6.958 & 250.74 & 0.26 \\
\hline 5.730 & 1006.04 & 0.56 & 6.143 & 953.89 & 0.53 & 6.908 & 815.22 & 0.47 & 8.149 & 711.65 & 0.44 \\
\hline 6.153 & 1008.20 & 0.56 & 6.569 & 956.81 & 0.53 & 7.302 & 822.50 & 0.47 & 8.354 & 722.16 & 0.44 \\
\hline 6.577 & 1010.33 & 0.56 & 6.995 & 959.73 & 0.53 & 7.696 & 829.61 & 0.48 & 8.728 & 736.08 & 0.44 \\
\hline 7.000 & 1012.43 & 0.56 & 7.421 & 962.56 & 0.54 & 8.090 & 836.37 & 0.48 & 9.174 & 748.97 & 0.44 \\
\hline 7.403 & 1014.33 & 0.56 & 7.846 & 965.35 & 0.54 & 8.484 & 842.04 & 0.48 & 9.529 & 759.15 & 0.45 \\
\hline 7.827 & 1016.39 & 0.56 & 8.272 & 968.06 & 0.54 & 8.878 & 847.70 & 0.48 & 9.883 & 768.37 & 0.45 \\
\hline 8.250 & 1018.40 & 0.56 & 8.698 & 970.64 & 0.54 & 9.272 & 852.96 & 0.49 & 10.238 & 776.48 & 0.45 \\
\hline 8.673 & 1020.37 & 0.56 & 9.104 & 973.03 & 0.54 & 9.666 & 858.07 & 0.49 & 10.593 & 784.19 & 0.46 \\
\hline 9.096 & 1022.21 & 0.56 & 9.530 & 975.47 & 0.54 & 10.060 & 862.77 & 0.49 & 10.947 & 791.11 & 0.46 \\
\hline 9.519 & 1024.10 & 0.56 & 9.956 & 977.78 & 0.54 & 10.454 & 867.10 & 0.49 & 11.302 & 797.53 & 0.46 \\
\hline 9.942 & 1025.97 & 0.56 & 10.382 & 980.13 & 0.54 & 10.848 & 871.28 & 0.49 & 11.657 & 803.31 & 0.46 \\
\hline 10.365 & 1027.75 & 0.57 & 10.807 & 982.46 & 0.54 & 11.242 & 875.44 & 0.50 & 12.011 & 809.06 & 0.47 \\
\hline 10.788 & 1029.56 & 0.57 & 11.233 & 984.78 & 0.55 & 11.636 & 879.41 & 0.50 & 12.366 & 814.51 & 0.47 \\
\hline 11.211 & 1031.23 & 0.57 & 11.659 & 986.95 & 0.55 & 12.030 & 883.07 & 0.50 & 12.721 & 819.51 & 0.47 \\
\hline 11.634 & 1032.95 & 0.57 & 12.085 & 989.14 & 0.55 & 12.424 & 886.61 & 0.50 & 13.075 & 824.13 & 0.47 \\
\hline 12.057 & 1034.75 & 0.57 & 12.510 & 991.26 & 0.55 & 12.818 & 890.28 & 0.50 & 13.430 & 828.67 & 0.48 \\
\hline 12.481 & 1036.38 & 0.57 & 12.936 & 993.38 & 0.55 & 13.212 & 893.80 & 0.50 & 13.785 & 833.10 & 0.48 \\
\hline 12.904 & 1038.07 & 0.57 & 13.362 & 995.42 & 0.55 & 13.606 & 897.17 & 0.51 & 14.139 & 837.31 & 0.48 \\
\hline 13.327 & 1039.71 & 0.57 & 13.788 & 997.45 & 0.55 & 14.000 & 900.40 & 0.51 & 14.494 & 841.26 & 0.48 \\
\hline 13.750 & 1041.31 & 0.57 & 14.214 & 999.50 & 0.55 & 14.394 & 903.44 & 0.51 & 14.849 & 844.88 & 0.48 \\
\hline 14.173 & 1042.90 & 0.57 & 14.639 & 1001.46 & 0.55 & 14.788 & 906.45 & 0.51 & 15.203 & 849.44 & 0.48 \\
\hline 14.596 & 1044.54 & 0.57 & 15.065 & 1003.43 & 0.55 & 15.182 & 909.27 & 0.51 & 15.558 & 853.17 & 0.49 \\
\hline 15.019 & 1046.08 & 0.57 & 15.491 & 1005.37 & 0.56 & 15.576 & 912.32 & 0.51 & 15.913 & 856.71 & 0.49 \\
\hline 15.442 & 1047.54 & 0.57 & 15.917 & 1007.25 & 0.56 & 15.970 & 915.21 & 0.51 & 16.267 & 860.21 & 0.49 \\
\hline 15.865 & 1049.06 & 0.58 & 16.342 & 1009.13 & 0.56 & 16.364 & 917.94 & 0.52 & 16.622 & 863.48 & 0.49 \\
\hline 16.288 & 1050.51 & 0.58 & 16.768 & 1010.91 & 0.56 & 16.758 & 920.64 & 0.52 & 16.977 & 866.80 & 0.49 \\
\hline 16.711 & 1052.02 & 0.58 & 17.194 & 1012.70 & 0.56 & 17.152 & 923.23 & 0.52 & 17.348 & 870.10 & 0.49 \\
\hline 17.135 & 1053.43 & 0.58 & 17.465 & 1013.86 & 0.56 & 17.546 & 925.79 & 0.52 & 17.703 & 873.19 & 0.50 \\
\hline 17.558 & 1054.90 & 0.58 & 17.755 & 1015.03 & 0.56 & 17.940 & 928.37 & 0.52 & 18.075 & 876.31 & 0.50 \\
\hline 17.981 & 1056.33 & 0.58 & 18.142 & 1016.64 & 0.56 & 18.334 & 930.88 & 0.52 & 18.446 & 879.36 & 0.50 \\
\hline 18.404 & 1057.71 & 0.58 & 18.529 & 1018.20 & 0.56 & 18.728 & 933.38 & 0.52 & 18.801 & 882.26 & 0.50 \\
\hline 18.827 & 1059.09 & 0.58 & 18.936 & 1019.78 & 0.56 & 19.015 & 935.11 & 0.52 & 19.156 & 884.97 & 0.50 \\
\hline 19.250 & 1060.46 & 0.58 & 19.323 & 1021.27 & 0.56 & 19.373 & 937.24 & 0.52 & 19.426 & 887.01 & 0.50 \\
\hline 19.673 & 1061.85 & 0.58 & 19.729 & 1022.82 & 0.56 & 19.731 & 939.35 & 0.52 & 19.747 & 889.44 & 0.50 \\
\hline 20.000 & 1062.87 & 0.58 & 20.000 & 1023.79 & 0.56 & 20.000 & 940.84 & 0.53 & 20.000 & 891.26 & 0.50 \\
\hline
\end{tabular}




\section{FIGURES}

(a)

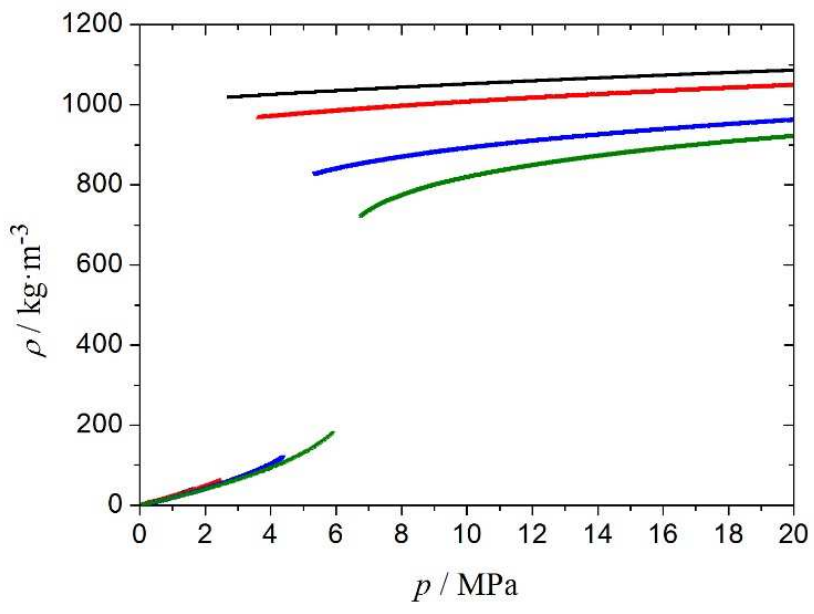

(b)

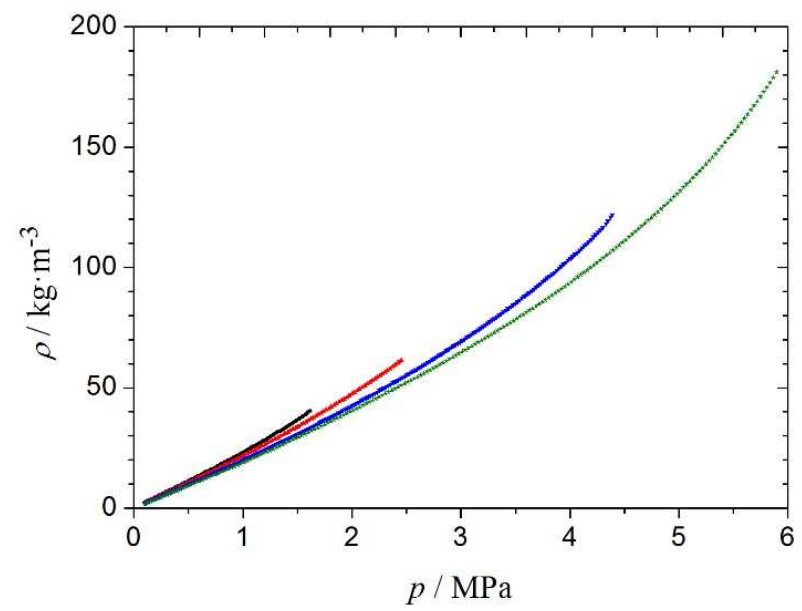

Figure 1. Experimental densities, $\rho$, of the $\mathrm{CO}_{2}+\mathrm{SO}_{2}$ mixture with $x_{\mathrm{CO}_{2}}=0.9532$ versus pressure, $p$, at several temperatures: $(\boldsymbol{\square}), T=263.15 \mathrm{~K} ;(\boldsymbol{\Delta}), T=273.15 \mathrm{~K} ;(\boldsymbol{\nabla}), T=293.15 \mathrm{~K}$; and ( $\star$ ), $T=304.21 \mathrm{~K}$. (a) Whole studied range of pressures. (b) Enlargement of the gas phase region. 


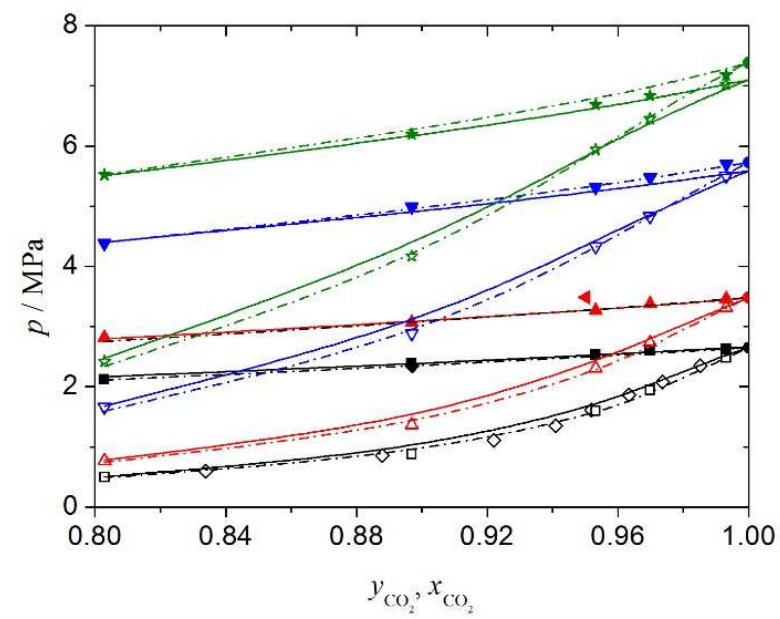

Figure 2. VLE for the $\mathrm{CO}_{2}+\mathrm{SO}_{2}$ system. Dew and bubble pressures versus composition of the vapor, $y_{\mathrm{CO}_{2}}$, and liquid, $x_{\mathrm{CO}_{2}}$, phases. Experimental data obtained in this work at several temperatures: $(\boldsymbol{\square}), T=263.15 \mathrm{~K} ;(\boldsymbol{\Delta}), T=273.15 \mathrm{~K} ;(\boldsymbol{\nabla}), T=293.15 \mathrm{~K}$; and $(\star), T=304.21 \mathrm{~K}$. $(\diamond)$, Experimental data at $T=263.15 \mathrm{~K}$ from Coquelet et al. ${ }^{62}(\triangleleft)$, Experimental data at $T=$ 273.56 K from Nazeri et al. ${ }^{32}$ Empty symbols, dew points; full symbols, bubble points. Solid lines: PC-SAFT EoS using the coefficients from Table S8. Dashed-dotted lines: extended EOSCG. Full circles: saturation pressures of pure $\mathrm{CO}_{2}$ at $263.15 \mathrm{~K}(\bullet), 273.15(\bigcirc)$, and 293.15 (O), ${ }^{55}$ and critical pressure at $304.21 \mathrm{~K}(\bigcirc) .{ }^{56}$ 


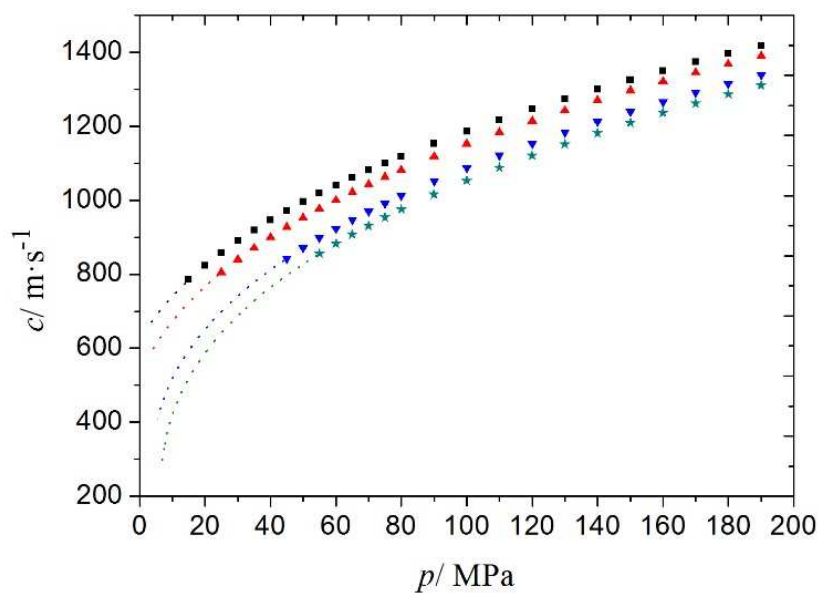

Figure 3. Experimental and extrapolated speed of sound, $c$, for the ternary $\mathrm{CO}_{2}+\mathrm{CH}_{3} \mathrm{OH}+\mathrm{SO}_{2}$ mixture with $x_{\mathrm{CO}_{2}}=0.9457, x_{\mathrm{CH}_{3} \mathrm{OH}}=0.0075$ and $x_{\mathrm{SO}_{2}}=0.0468$ versus pressure, $p$, at several temperatures: $(\boldsymbol{\square}), T=263.15 \mathrm{~K} ;(\boldsymbol{\Delta}), T=273.15 \mathrm{~K} ;(\boldsymbol{\nabla}), T=293.15 \mathrm{~K}$; and $(\star), T=304.21 \mathrm{~K}$. Symbols: experimental; dotted lines: extrapolated.

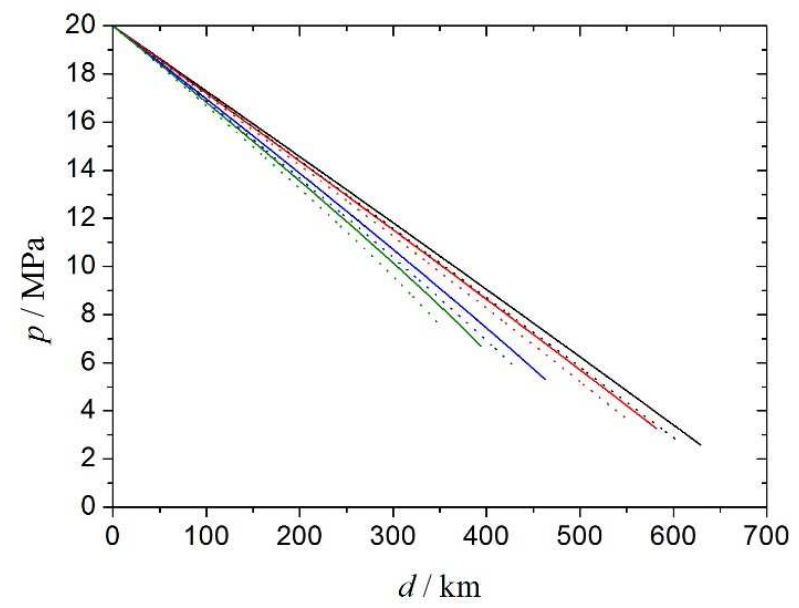

Figure 4. Comparison of pressure profiles along the pipeline for the $\mathrm{CO}_{2}+\mathrm{SO}_{2}$ mixture with $x_{\mathrm{CO}_{2}}=0.9532$ (solid lines) and pure $\mathrm{CO}_{2}$ (dotted lines) at several transport temperatures: $(-)$, $T=263.15 \mathrm{~K} ;(-), T=273.15 \mathrm{~K} ;(-), T=293.15 \mathrm{~K}$; and $(-), T=304.21 \mathrm{~K}$. Mass flow $m=$ 
$317.1 \mathrm{~kg} / \mathrm{s}$, inner diameter of the pipeline $D=0.508 \mathrm{~m}$, and roughness height $e=4.6 \times 10^{-5} \mathrm{~m}$ were used along with a pipeline inlet pressure of $20.00 \mathrm{MPa}$.

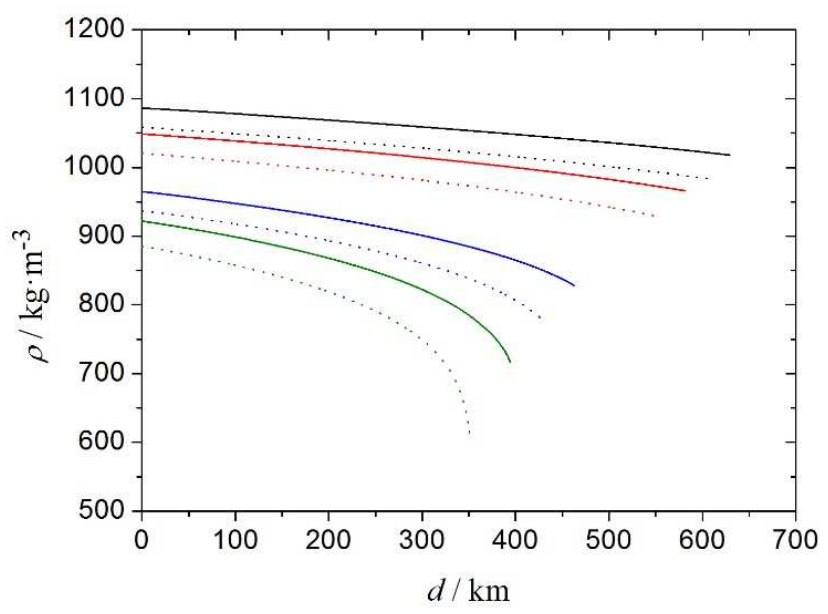

Figure 5. Comparison of density profiles along the pipeline for the $\mathrm{CO}_{2}+\mathrm{SO}_{2}$ mixture with $x_{\mathrm{CO}_{2}}=0.9532$ (solid lines) and pure $\mathrm{CO}_{2}$ (dotted lines) at various transport temperatures: (-), $T=263.15 \mathrm{~K} ;(-), T=273.15 \mathrm{~K} ;(-), T=293.15 \mathrm{~K}$; and $(-), T=304.21 \mathrm{~K}$. Mass flow $m=$ $317.1 \mathrm{~kg} / \mathrm{s}$, inner diameter of the pipeline $D=0.508 \mathrm{~m}$, and roughness height $e=4.6 \times 10^{-5} \mathrm{~m}$ were used along with a pipeline inlet pressure of $20.00 \mathrm{MPa}$.

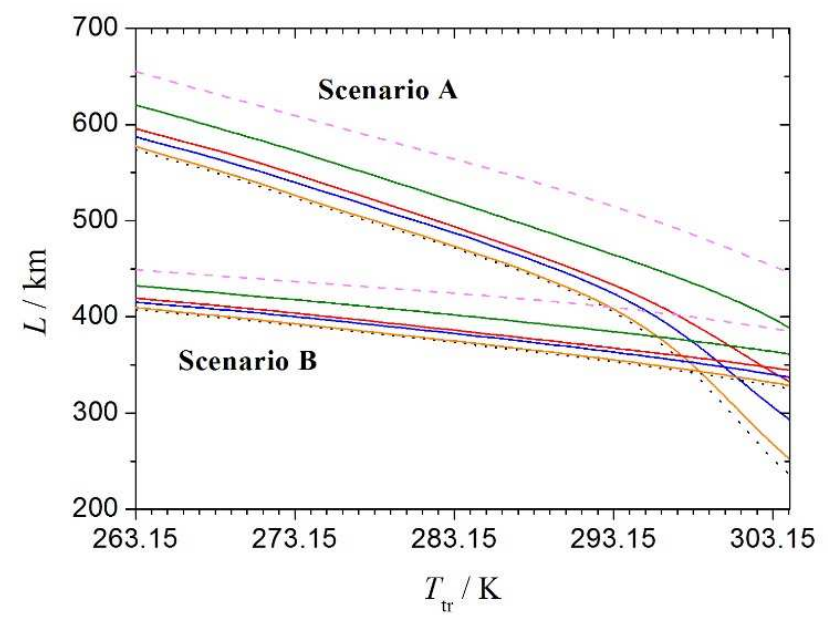


Figure 6. Maximum repressurization (pumping) distances, $L$, versus transport temperature, $T_{\mathrm{tr}}$, for the $\mathrm{CO}_{2}+\mathrm{SO}_{2}$ studied mixtures and pure $\mathrm{CO}_{2}:(--=), x_{\mathrm{CO}_{2}}=0.8029 ;(-), x_{\mathrm{CO}_{2}}=0.8969$; $(-), x_{\mathrm{CO}_{2}}=0.9532 ;(-), x_{\mathrm{CO}_{2}}=0.9698 ;(-), x_{\mathrm{CO}_{2}}=0.9931 ;(\cdots \cdots)$, pure $\mathrm{CO}_{2}$. Scenario A: $L$ required to maintain the pressure above $p_{\text {saf. }}$ Scenario B: $L$ required to maintain the pressure above $8.5 \mathrm{MPa}$. Mass flow was taken to be $m=317.1 \mathrm{~kg} / \mathrm{s}$, inner diameter of the pipeline $D=$ $0.508 \mathrm{~m}$, and roughness height $e=4.6 \times 10^{-5} \mathrm{~m}$. The pipeline inlet pressure was set at $20.00 \mathrm{MPa}$.

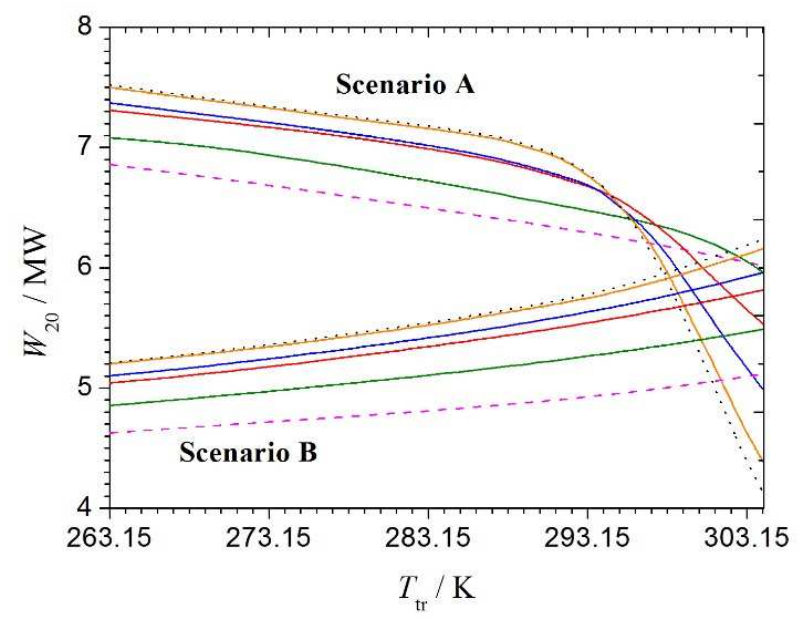

Figure 7. Booster station power, $W_{20}$, required to repressurize the fluid up to an outlet pressure and temperature of $20.00 \mathrm{MPa}$ and $311 \mathrm{~K}$ versus the transport (= inlet) temperature, $T_{\mathrm{tr}}$, for the $\mathrm{CO}_{2}+\mathrm{SO}_{2}$ studied mixtures and pure $\mathrm{CO}_{2}:(--=), x_{\mathrm{CO}_{2}}=0.8029 ;(-), x_{\mathrm{CO}_{2}}=0.8969 ;(-)$, $x_{\mathrm{CO}_{2}}=0.9532 ;(-), x_{\mathrm{CO}_{2}}=0.9698 ;(-), x_{\mathrm{CO}_{2}}=0.9931 ;(\cdots \cdots)$, pure $\mathrm{CO}_{2}$. Scenario A: $W_{20}$ necessary to repressurize from $p_{\text {saf }}$ at $T_{\mathrm{tr}}$. Scenario B: $W_{20}$ necessary to repressurize from 8.5 $\mathrm{MPa}$ at $T_{\mathrm{tr}}$. Mass flow was taken to be $m=317.1 \mathrm{~kg} / \mathrm{s}$, inner diameter of the pipeline $D=0.508$ $\mathrm{m}$, roughness height $e=4.6 \times 10^{-5} \mathrm{~m}$, and booster efficiency $y_{\text {booster }}=0.75$. 


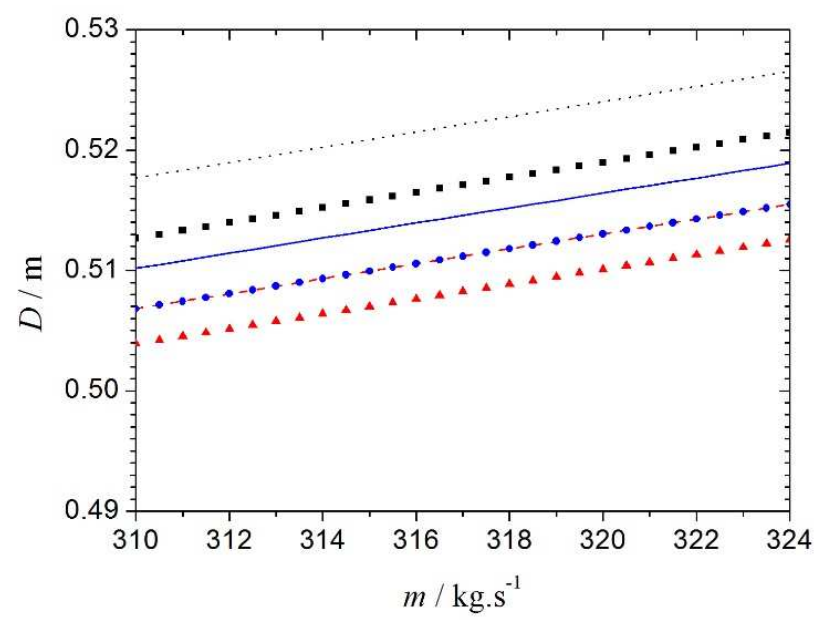

Figure 8. Pipeline inner diameter, $D$, versus mass flow (capacity), $m$, for the $\mathrm{CO}_{2}+\mathrm{SO}_{2}$ mixture with $x_{\mathrm{CO}_{2}}=0.9532$ and pure $\mathrm{CO}_{2}$ at $293.15 \mathrm{~K}$ and the following pressures: $(\mathbf{\square}, \cdots) 8.50 \mathrm{MPa}$; $(\mathbf{O},-) 15.00 \mathrm{MPa},(\boldsymbol{\Delta},-\cdot-)$ 20.00 MPa. Symbols, mixture; lines, pure $\mathrm{CO}_{2}$. Roughness height was set at $e=4.6 \times 10^{-5} \mathrm{~m}$ and an average value for pressure drop per meter of $30 \mathrm{~Pa} \cdot \mathrm{m}^{-1}$ was used.

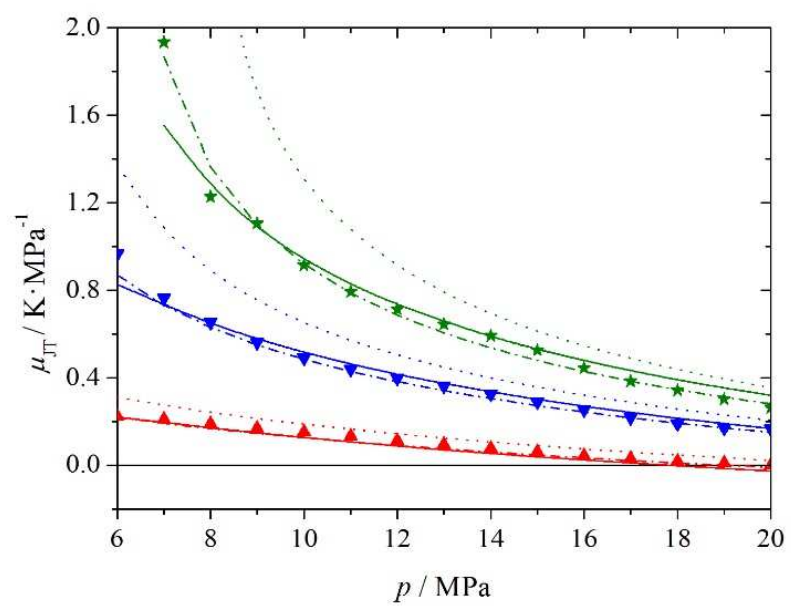


Figure 9. Calculated Joule-Thomson coefficient, $\mu_{\mathrm{JT}}$, at several pressures, $p$, and temperatures, $T$, for the $\mathrm{CO}_{2}+\mathrm{SO}_{2}$ mixture with $x_{\mathrm{SO}_{2}}=0.0468$, and for pure $\mathrm{CO}_{2}$. Symbols, this work. Solid lines, PC-SAFT EoS using coefficients from Table S8. Dashed-dotted lines, extended EOS-CG. Dotted lines, pure $\mathrm{CO}_{2} .{ }^{55}(\boldsymbol{\Delta}), T=273.15 \mathrm{~K} ;(\boldsymbol{\nabla}), T=293.15 \mathrm{~K}$; and $(\star), T=304.21 \mathrm{~K}$.

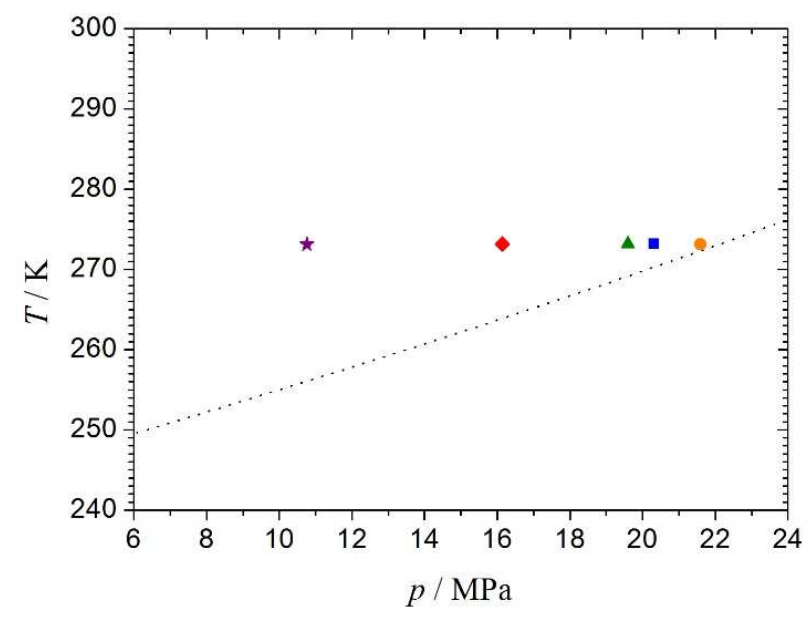

Figure 10. Joule-Thomson inversion pressures of the $\mathrm{CO}_{2}+\mathrm{SO}_{2}$ studied mixtures at $273.15 \mathrm{~K}$ and inversion line of pure $\mathrm{CO}_{2}{ }^{55}$ Symbols, values calculated in this work for the mixtures: $(\odot)$, $x_{\mathrm{SO}_{2}}=0.0069 ;(\square), x_{\mathrm{SO}_{2}}=0.0302 ;(\Delta), x_{\mathrm{SO}_{2}}=0.0468 ;(\diamond), x_{\mathrm{SO}_{2}}=0.1031 ;(\star), x_{\mathrm{CO}_{2}}=$ 0.1917. 


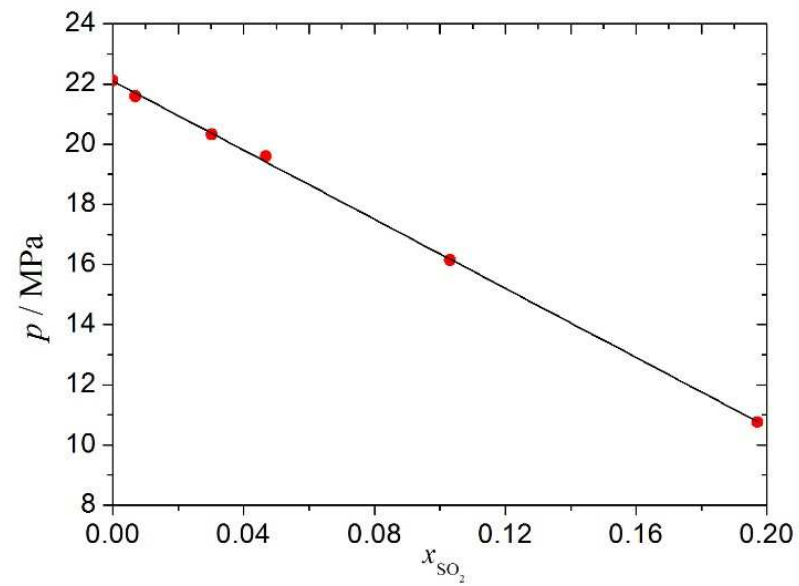

Figure 11. Correlation of the Joule-Thomson inversion pressures of the studied $\mathrm{CO}_{2}+\mathrm{SO}_{2}$ mixtures with the $\mathrm{SO}_{2}$ mole fraction at $273.15 \mathrm{~K}$. Data for pure $\mathrm{CO}_{2}$ from Span and Wagner $\operatorname{EoS}^{55}$ as implemented in REFPROP 9.1. ${ }^{76}$

\section{ASSOCIATED CONTENT}

\section{Supporting Information.}

The Supporting Information is available free of charge on the ACS Publications website at DOI:

Experimental and calculated data tables and additional figures as presented in the text (PDF).

\section{AUTHOR INFORMATION}

\section{Corresponding Author}

*Tel: +34 976761206. E-mail: javierf@unizar.es.

\section{ORCID}

Javier Fernández: 0000-0001-5256-6055 
Beatriz Gimeno: 0000-0002-6992-5656

Manuela Artal: $\quad$ 0000-0003-1810-9488

Inmaculada Velasco: 0000-0001-6607-6858

Sofía T. Blanco: 0000-0003-2632-2916

\section{Funding Sources}

This work was supported by the Ministry of Economy and Competitiveness of Spain [ENE2013-

44336-R], Government of Aragon [E32 23317/3], and University of Zaragoza [23321, 23326, 23327, 23328, and 23329].

\section{Notes}

The authors declare no competing financial interest.

\section{ACKNOWLEDGMENTS}

The authors acknowledge to their funding sources and thank Dr. Roland Span and Mr. Stefan Herrig for making the TREND 2.0.1 software available, and Dr. Luis Rández for computing assistance.

\section{ABBREVIATIONS}

CCS carbon capture and storage; VLE vapor-liquid equilibrium.

\section{REFERENCES}

(1) Dlugokencky, E.; Tans, P. NOAA/ESRL. Trends in atmospheric carbon dioxide. Web site. www.esrl.noaa.gov/gmd/ccgg/trends/ (accessed May 10, 2018). 
(2) Hansen, J.; Sato, M.; Kharecha, P.; Beerling, D.; Berner, R.; Masson-Delmotte, V.;

Pagani, M.; Raymo, M.; Royer, D. L.; Zachos, J. C. et al. Target atmospheric $\mathrm{CO}_{2}$ : Where should humanity aim? Open Atmos. Sci. J. 2008, 2, 217-231.

http://dx.doi.org/10.2174/1874282300802010217.

(3) Allen, M. R.; Frame, D. J.; Huntingford, C.; Jones, C. D.; Lowe, J. A.; Meinshausen, M.; Meinshausen, N. Warming caused by cumulative carbon emissions towards the trillionth tonne. Nature 2009, 458, 1163-1166. http://dx.doi.org/10.1038/nature08019.

(4) The Paris Agreement; Framework Convention on Climate Change. United Nations. Web site. http://unfccc.int/paris_agreement/items/9485.php (accessed May 10, 2018)

(5) The global Status of CCS: 2016; Global CCS Institute; Melbourne, Australia. Web site. https://hub.globalccsinstitute.com/sites/default/files/publications/201158/global-status-ccs2016-summary-report.pdf (accessed May 10, 2018).

(6) Figueroa, J. D.; Fout, T.; Plasynski, S.; McIlvried, H.; Srivastava, R. D. Advances in $\mathrm{CO}_{2}$ capture technology - The US Department of Energy's Carbon Sequestration Program. Int. J. Greenh. Gas Control 2008, 2 (1), 9-20. http://dx.doi.org/10.1016/S1750-5836(07)00094-1.

(7) MacDowell, N.; Florin, N.; Buchard, A.; Hallett, J.; Galindo, A.; Jackson, G.; Adjiman, C. S.; Williams, C. K.; Shahb, N.; Fennell, P. An overview of $\mathrm{CO}_{2}$ capture technologies. Energ. Environ. Sci. 2010, 3 (11), 1645-1669. http://dx.doi.org/10.1039/c004106h.

(8) Olajire, A. A. $\mathrm{CO}_{2}$ capture and separation technologies for end-of-pipe applications - A review. 7th International Conference on Sustainable Energy Technologies. Liverpool, England, Feb 20-21, 2008.

(9) Bandyopadhyay, A.; Luo, G.; Fei, W. Preface. Special issue: $\mathrm{CO}_{2}$ Capture and Storage. Sep. Purif. Technol. 2012, 94, 85-86. https://doi.org/10.1016/j.seppur.2012.02.012. 
(10) Svenson, R.; Odenberger, M.; Johnsson, F.; Strömberg, L. Transportation infrastructure for CCS- Experiences and expected development. In Greenhouse gas control technologies; Wilson, M.; Morris, T.; Gale, J.; Thambimuthu, K., Eds.; Elsevier Ltd; 2005; Vol. II, pp 25312534.

(11) Doctor, R.; Palmer, A.; Coleman, D.; Davison, J.; Hendricks, C.; Kaarstad, O.; Ozaki, M.; Austell, M. Transport of $\mathrm{CO}_{2}$. In IPCC Special Report on Carbon Dioxide Capture and Storage; Metz, B.; Davidson, O.; de Coninck, H.; Loos, M.; Meyer, L.; Eds.; Cambridge University Press, 2005; pp 179-193. Web site. https://www.ipcc.ch/report/srccs/ (accessed May $10,2018)$

(12) Zhang, Z. X.; Wang, G. X.; Massarotto, P.; Rudolph, V. Optimization of pipeline transport for $\mathrm{CO}_{2}$ sequestration. Energy Convers. Manag. 2006, 47, 702-715. https://doi.org/10.1016/j.enconman.2005.06.001.

(13) McCoy, S. T.; Rubin, E. S. An engineering-economic model of pipeline transport of $\mathrm{CO}_{2}$ with application to carbon capture and storage. Int. J. Greenh. Gas Control 2008, 2, 219-229. https://doi.org/10.1016/S1750-5836(07)00119-3.

(14) Knoope, M. M. J.; Ramírez, A.; Faaij, A. P. C. A state-of-the-art review of technoeconomic models predicting the costs of $\mathrm{CO}_{2}$ pipeline transport. Int. J. Greenh. Gas Control 2013, 16 (1), 241-270. https://doi.org/10.1016/j.ijggc.2013.01.005.

(15) Knoope, M. M. J.; Guijt, W.; Ramírez, A.; Faaij, A. P. C. Improved cost models for optimizing $\mathrm{CO} 2$ pipeline configuration for point-to-point pipelines and simple networks. Int. J. Greenh. Gas Control 2014, 22 (1), 25-46. http://dx.doi.org/10.1016/j.ijggc.2013.12.016.

(16) Geologic Storage of Carbon Dioxide; International Energy Agency; Greenhouse Gas R\&D Programme, January 2008. Web site. 
http://www.ccsassociation.org/docs/2008/IEA\%20GHG\%20geological\%20storage\%20of\%20C O2\%20February\%2008.pdf (accessed May 10, 2018).

(17) Energy Technology Perspectives 2017: Catalysing Energy Technology Transformations; International Energy Agency, 2017. Web site.

https://www.iea.org/publications/freepublications/publication/EnergyTechnologyPerspectives2 017ExecutiveSummaryEnglishversion.pdf (accessed May 10, 2018).

(18) The global Status of CCS: 2017; Global CCS Institute, 2017. Web site.

http://www.globalccsinstitute.com/sites/www.globalccsinstitute.com/files/uploads/globalstatus/1-0_4529_CCS_Global_Status_Book_layout-WAW_spreads.pdf (accessed May 10, 2018).

(19) World Energy Outlook 2009; International Energy Agency, 2009. Web site. http://www.worldenergyoutlook.org/media/weowebsite/2009/WEO2009.pdf (accessed May 10, 2018)

(20) $\mathrm{CO}_{2}$ Pipeline Infrastructure. International Energy Agency 2014. IEAGHG Report 2013/18, January 2014. Web site. http://ieaghg.org/docs/General_Docs/Reports/2013-18.pdf (accessed May 10, 2018).

(21) Løvseth, S.; Skaugen, G.; Stang, H. G. J.; Jakobsen, J. P.; Wilhelmsen, Ø.; Span, R.; Wegge, R. $\mathrm{CO}_{2}$ Mix Project: Experimental determination of thermophysical properties of $\mathrm{CO}_{2}-$ rich mixtures. Energy Procedia 2013, 37, 2889-2896.

http://dx.doi.org/10.1016/j.egypro.2014.09.002.

(22) Porter, R. T. J.; Fairweather, M.; Pourkashanian, M.; Woolley, R. M. The range and level of impurities in $\mathrm{CO}_{2}$ streams from different carbon capture sources. Int. J. Greenh. Gas Control 2015, 36, 161-174. http://dx.doi.org/10.1016/j.ijggc.2015.02.016. 
(23) Wang, J.; Ryan, D.; Anthony, E. J.; Wildgust, N.; Aiken, T. Effects of Impurities on $\mathrm{CO}_{2}$ Transport, Injection and Storage. Energy Procedia 2011, 4, 3071-3078.

http://dx.doi.org/10.1016/j.egypro.2011.02.219.

(24) Ziabakhsh-Ganji, Z.; Kooi, H. Sensitivity of the $\mathrm{CO}_{2}$ storage capacity of underground geological structures to the presence of $\mathrm{SO}_{2}$ and other impurities. Appl. Energy 2014, 135, 43-

52. http://dx.doi.org/10.1016/j.apenergy.2014.08.073.

(25) Koenen, M.; Waldmann, S.; Hofstee, C.; Neele, F. Effect of $\mathrm{SO}_{2}$ co-injection on $\mathrm{CO}_{2}$ storage. Presented at $2^{\text {nd }}$ International Forum on Recent Developments of CCS Implementations, Athens, $16^{\text {th }}-17^{\text {th }}$ December, 2015.

(26) Wang, J.; Wang, Z. Y.; Ryan, D.; Lan, C. A study of the effect of impurities on $\mathrm{CO}_{2}$ storage capacity in geological formations. Int. J. Greenh. Gas Control 2015, 42, 132-137. http://dx.doi.org/10.1016/j.ijggc.2015.08.002.

(27) Ziabakhsh-Ganji, Z. Physical and geochemical impacts of impure $\mathrm{CO}_{2}$ on storage in depleted hydrocarbon reservoirs and saline aquifers. Ph.D. Thesis, University of Amsterdam, the Netherlands, 2015.

(28) Crandell, L. E.; Ellis, B. R.; Peters, C. A. Dissolution Potential of $\mathrm{SO}_{2}$ Co-Injected with $\mathrm{CO}_{2}$ in Geologic Sequestration. Environ. Sci. Technol. 2010, 44, 349-355. http://dx.doi.org/10.1021/es902612m.

(29) Xiang, Y.; Wang, Z.; Yang, X.; Li, Z.; Ni, W. The upper limit of moisture content for supercritical CO2 pipeline transport. J. Supercrit. Fluids 2012, 67, 14-21.

https://doi.org/10.1016/j.supflu.2012.03.006. 
(30) Miri, R.; Aagaard, P.; Hellevang, H. Examination of $\mathrm{CO}_{2}-\mathrm{SO}_{2}$ Solubility in Water by SAFT1. Implications for $\mathrm{CO}_{2}$ Transport and Storage. J. Phys. Chem. B 2014, 118 (34), 1021410223. http://dx.doi.org/10.1021/jp505562j.

(31) Kim, M. C.; Song, K. H. Effect of impurities on the onset and growth of gravitational instabilities in a geological $\mathrm{CO}_{2}$ storage process: Linear and nonlinear analyses. Chem. Eng. Sci. 2017, 174, 426-444. https://doi.org/10.1016/j.ces.2017.09.038.

(32) Nazeri, M.; Chapoy, A.; Valtz, A.: Coquelet, C.; Tohidi, B. New experimental density data and derived thermophysical properties of carbon dioxide - Sulphur dioxide binary mixture $\left(\mathrm{CO}_{2}-\mathrm{SO}_{2}\right)$ in gas, liquid and supercritical phases from $273 \mathrm{~K}$ to $353 \mathrm{~K}$ and at pressures up to 42 MPa. Fluid Phase Equilibr. 2017, 454, 64-77. https://doi.org/10.1016/j.fluid.2017.09.014.

(33) Rivas, C.; Gimeno, B.; Artal, M.; Blanco, S. T.; Fernández, J.; Velasco, I. High-pressure speed of sound in pure $\mathrm{CO}_{2}$ and in $\mathrm{CO}_{2}$ with $\mathrm{SO}_{2}$ as an impurity using methanol as a doping agent. Int. J. Greenh. Gas Control 2016, 54, 737-751.

http://dx.doi.org/10.1016/j.ijggc.2016.09.014.

(34) Gimeno, B.; Artal, M.; Velasco, I.; Blanco, S. T.; Fernández J. Influence of $\mathrm{SO}_{2}$ on $\mathrm{CO}_{2}$ storage for CCS technology: Evaluation of $\mathrm{CO}_{2} / \mathrm{SO}_{2}$ co-capture. Appl. Energy 2017, 206, 172180. https://doi.org/10.1016/j.apenergy.2017.08.048.

(35) Gross, J.; Sadowski, G. Perturbed-Chain SAFT: An Equation of State based on a perturbation theory for chain molecules. Ind. Eng. Chem. Res. 2001, 40 (4), 1244-1260. http://dx.doi.org/10.1021/ie0003887.

(36) Gernert, J; Span, R. EOS-CG: A Helmholtz energy mixture model for humid gases and CCS mixtures. J. Chem. Thermodyn. 2016, 93, 274-293.

http://dx.doi.org/10.1016/j.jct.2015.05.015. 
(37) Span, R.; Eckermann, T.; Herrig, S.; Hielscher, S.; Jäger, A.; Thol, M. TREND.

Thermodynamic Reference and Engineering Data 2.0.1. Lehrstuhl fuer Thermodynamik, RuhrUniversitaet Bochum, 2015.

(38) Cole, I. S.; Corrigan, P.; Sim, S.; Birbilis, N. Corrosion of pipelines used for $\mathrm{CO}_{2}$

transport in CCS: Is it a real problem? Int. J. Greenh. Gas Control 2011, 5, 749-756.

http://dx.doi.org/10.1016/j.ijggc.2011.05.010.

(39) Dugstad, A.; Morland, B.; Clausen, S. Corrosion of transport pipelines for $\mathrm{CO}_{2}-$ effect of water ingress. Energy Procedia 2011, 4, 3063-3070.

http://dx.doi.org/10.1016/j.egypro.2011.02.218.

(40) Xiang, Y.; Wang, Z.; Xu, C.; Zhou, C.; Li, Z.; Ni, W. Impact of $\mathrm{SO}_{2}$ concentration on the corrosion rate of X70 steel and iron in water-saturated supercritical $\mathrm{CO}_{2}$ mixed with $\mathrm{SO}_{2} . J$. Supercrit. Fluids 2011, 58, 286-294. https://doi.org/10.1016/j.supflu.2011.06.007.

(41) Paschke, B.; Kather, A. Corrosion of Pipeline and Compressor Materials due to Impurities in separated $\mathrm{CO}_{2}$ from fossil-fuelled Power Plants. Energy Procedia 2012, 23, 207215. http://dx.doi.org/10.1016/j.egypro.2012.06.030.

(42) Rhul, A. S.; Kranzmann, A. Corrosion in supercritical $\mathrm{CO}_{2}$ by diffusion of flue gas acids and water. J. Supercrit. Fluids 2012, 68, 81-86. https://doi.org/10.1016/j.supflu.2012.04.015. (43) Dugstad, A.; Halseid, M.; Morland, B. Effect of $\mathrm{SO}_{2}$ and $\mathrm{NO}_{2}$ on corrosion and solid formation in dense phase $\mathrm{CO}_{2}$ pipelines. Energy Procedia 2013, 37, 2877-2887. http://dx.doi.org/10.1016/j.egypro.2013.06.173.

(44) Farelas, F.; Choi, Y. S.; Nešić, S. Corrosion Behavior of API 5L X65 Carbon Steel Under Supercritical and Liquid Carbon Dioxide Phases in the Presence of Water an Sulfur Dioxide. Corrosion 2013, 69 (3), 243-250. http://dx.doi.org/10.5006/0739. 
(45) Brown, J.; Graver, B.; Gulbrandsen, E.; Dugstad, A.; Morland, B. Update of DNV recommended practice RP-J202 with focus on $\mathrm{CO}_{2}$ Corrosion with Impurities. Energy Procedia 2014, 6, 2432-2441. http://dx.doi.org/10.1016/j.egypro.2014.11.265.

(46) Hua, Y.; Barker, R.; Neville, A. The influence of $\mathrm{SO}_{2}$ on the tolerable water content to avoid pipeline corrosion during the transportation of supercritical $\mathrm{CO}_{2}$. Int. J. Greenh. Gas Control 2015, 37, 412-423. https://doi.org/10.1016/j.ijggc.2015.03.031.

(47) Velasco, I.; Rivas, C.; Martínez-López, J. F.; Blanco, S. T.; Otín, S.; Artal, M. Accurate values of some thermodynamic properties for carbon dioxide, ethane, propane, and some binary mixtures. J. Phys. Chem. B 2011, 115 (25), 8216-8230. http://dx.doi.org/10.1021/jp202317n. (48) Blanco, S. T.; Rivas, C.; Bravo, R.; Fernández, J.; Artal, M.; Velasco, I. Discussion on the influence of $\mathrm{CO}$ and $\mathrm{CH}_{4}$ in $\mathrm{CO}_{2}$ transport, injection, and storage for $\mathrm{CCS}$ technology. Environ. Sci. Technol. 2014, 48 (18), 10984-10992. http://dx.doi.org/10.1021/es502306k. (49) Procedimiento TH-006 para la calibración de termómetros de resistencia de platino. Área de Temperatura. Centro Español de Metrología. Ministerio de Industria, Turismo y Comercio. Editorial/NIPOP/ISBN: 165-00-006-1; 2000.

(50) Bouchot, C.; Richon, D. Direct pressure-volume-temperature and vapor-liquid equilibrium measurements with a single equipment using a vibrating tube densimeter up to 393 $\mathrm{K}$ and $40 \mathrm{MPa}$ : Description of the original apparatus and new data. Ind. Eng. Chem. Res. 1998, 37 (8), 3295-3304. http://dx.doi.org/10.1021/ie970804w.

(51) Li, H.; Jakobsen, J. P.; Wilhelmsen, Ø.; Yan, J. PVTxy properties of $\mathrm{CO}_{2}$ mixtures relevant for $\mathrm{CO}_{2}$ capture, transport and storage: Review of available experimental data and theoretical models. Appl. Energy 2011, 88 (11), 3567-3579.

http://dx.doi.org/10.1016/j.apenergy.2011.03.052. 
(52) Serpa, J.; Morbee, J.; Tzimas, E. Technical and Economic Characteristics of a $\mathrm{CO}_{2}$ Transmission Pipeline Infrastructure; European Commission; Joint Research Centre; Institute of Energy, 2011. JRC62502. Web site.

http://publications.jrc.ec.europa.eu/repository/bitstream/111111111/16038/1/reqno_jrc62502_a spublished.pdf (accessed May 10, 2018).

(53) Annual European Union greenhouse gas inventory 1990-2015 and inventory report 2017; EEA Report No 6/2017; European Environment Agency, 2017. Web site. https://www.eea.europa.eu/publications/european-union-greenhouse-gas-inventory-2017 (accessed May 10, 2018).

(54) Inventory of U.S. greenhouse gas emissions and sinks: 1990 - 2015; EPA 430-P-17-001; U.S. Environmental Protection Agency, 2017. Web site. https://www.epa.gov/ghgemissions/inventory-us-greenhouse-gas-emissions-and-sinks-1990$\underline{2015}$ (accessed May 10, 2018).

(55) Span, R.; Wagner, W. A new equation of state for carbon dioxide covering the fluid region from the triple-point temperature to $1100 \mathrm{~K}$ at pressures up to $800 \mathrm{MPa}$. J. Phys. Chem. Ref. Data 1996, 25 (6), 1509-1596. https://doi.org/10.1063/1.555991.

(56) Gil, L.; Otin, S. F.; Muñoz Embid, J.; Gallardo, A.; Blanco, S. T.; Artal, M.; Velasco, I. Experimental setup to measure critical properties of pure and binary mixtures and their densities at different pressures and temperatures. Determination of the precision and uncertainty in the results. J. Supercrit. Fluids 2008, 44, 123-138.

http://dx.doi.org/10.1016/j.supflu.2007.11.003. 
(57) Blümcke, A. Ueber die Bestimmung der specifischen Gewichte und Dampfspannungen einiger Gemische von schwefliger Säure und Kohlensäure. Ann. Phys-Leipzig. 1888, 270 (5), 10-21. http://dx.doi.org/10.1002/andp.18882700503.

(58) Caubet, F. Liquéfaction des mélanges gazeux. Ph.D. Thesis, Université de Bordeaux, France, 1901.

(59) Thiel, A.; Schulte, E. Über binäre Gleichgewichtssysteme mit festem Kohlendioxyd. Z. Phys. Chem-Stoch Ve. 1920, 96 (3/4), 312-342. https://doi.org/10.1515/zpch-1920-9611.

(60) Cummings, L. W. T. High-pressure rectification I - Vapor-liquid equilibrium relations at high pressures. Ind. Eng. Chem. 1931, 23, 900-902. https://doi.org/10.1021/ie50260a010.

(61) Lachet, V.; de Bruin, T.; Ungerer, P.; Coquelet, C.; Valtz, A.; Hasanov, V.; Lockwood, F.; Richon, D. Thermodynamic behavior of the $\mathrm{CO}_{2}+\mathrm{SO}_{2}$ mixture: experimental and Monte Carlo simulation studies. Energy Procedia 2009, 1 (1), 1641-1647. http://dx.doi.org/10.1016/j.egypro.2009.01.215.

(62) Coquelet, C.; Valtz, A.; Arpentinier, P. Thermodynamic study of binary and ternary systems containing $\mathrm{CO}_{2}+$ impurities in the context of $\mathrm{CO}_{2}$ transportation. Fluid Phase Equilibr. 2014, 382, 205-211. http://dx.doi.org/10.1016/j.fluid.2014.08.031.

(63) ThermoLit. NIST Literature Report Builder for Thermophysical and Thermochemical Property Measurements. NIST Standard Reference Database \#171. Web site. http://trc.nist.gov/thermolit/main/home.html\#home (accessed May 10, 2018).

(64) Wilhelmsen, Ø.; Skaugen, G.; Jørstad, O.; Li, H. Evaluation of SPUNG and other Equations of State for use in Carbon Capture and Storage modelling. Energy Procedia 2012, 23, 236-245. http://dx.doi.org/10.1016/j.egypro.2012.06.024. 
(65) Diamantonis, N. I.; Boulougouris., G. C.; Tsangaris, D. M.; El Kadi, M.; Saadawi, H.; Economou, I. G. Thermodynamic and transport property models for carbon capture and sequestration (CCS) processes with emphasis on $\mathrm{CO}_{2}$ transport. Chem. Eng. Res. Des. 2013, 91 (10), 1793-1806. http://dx.doi.org/10.1016/j.cherd.2013.06.017.

(66) Seevam, P. N.; Race, J. M.; Downie, J. M.; Hopkins P. Transporting the next generation of $\mathrm{CO}_{2}$ for carbon, capture and storage: the impact of impurities on supercritical $\mathrm{CO}_{2}$ pipelines. Proceedings of IPC2008, $7^{\text {th }}$ International Pipeline Conference, Calgary, Alberta, Canada, September 29-October 3, 2008; IPC2008-64063.

(67) Kunz, O.; Klimeck, R.; Wagner, W.; Jaeschke, M. The GERG 2004 Wide range equation of state for natural gases and other mixtures; Technical Monograph GERG TM15 2007. VDIVerlag GmbH; Dusseldorf, Germany, 2007.

(68) Gao, K.; Wu, J.; Zhang, P.; Lemmon, E. W. A Helmholtz Energy Equation of State for Sulfur Dioxide. J. Chem. Eng. Data 2016, 61 (8), 2859-2872.

http://dx.doi.org/10.1021/acs.jced.6b00195.

(69) Laursen, T. VLXE ApS. Scion-DTU, Diplomvej, Denmark, 2012.

(70) Rivas, C.; Blanco, S. T.; Fernández, J.; Artal, M.; Velasco, I. Influence of methane and carbon monoxide in the volumetric behaviour of the anthropogenic $\mathrm{CO}_{2}$ : Experimental data and modelling in the critical region. Int. J. Greenh. Gas Control 2013, 18, 264-276. http://dx.doi.org/10.1016/j.ijggc.2013.07.019.

(71) Diamantonis, N. I.; Boulougouris, G. C.; Mansoor, E.; Tsangaris, D. M.; Economou, I. G. Evaluation of cubic, SAFT, and PC-SAFT equations of state for the vapor-liquid equilibrium modeling of $\mathrm{CO}_{2}$ mixtures with other gases. Ind. Eng. Chem. Res. 2013, 52 (10), 3933-3942. http://dx.doi.org/10.1021/ie303248q. 
(72) Xu, X.; Privat, R.; Jaubert, J. N.; Lachet, V.; Creton, B. Phase equilibrium of CCS mixtures: Equation of state modeling and Monte Carlo simulation. J. Supercrit. Fluid 2017, 119, 169-202. http://dx.doi.org/10.1016/j.supflu.2016.09.013.

(73) Vandeginste, V.; Piessens, K. Pipeline design for a least - cost router application for $\mathrm{CO}_{2}$ transport in the $\mathrm{CO}_{2}$ sequestration cycle. Int. J. Greenh. Gas Control 2008, 2 (4), 571-581. http://dx.doi.org/10.1016/j.ijggc.2008.02.001.

(74) ElementEnergy, 2010. $\mathrm{CO}_{2}$ pipeline infrastructure; An analysis of global challenges and opportunities; Final report for IEA Greenhouse Gas Programme, 27/04/2010. Web site. http://www.ccsassociation.org/docs/2010/IEA\%20Pipeline\%20final\%20report\%20270410.pdf (accessed May 10, 2018).

(75) Klein, S. A.; McLinden, M. O.; Laesecke, A. An improved extended corresponding states method for estimation of viscosity of pure refrigerants and mixtures. Int. J. Refrig. 1997, 20, 208-217. http://dx.doi.org/10.1016/S0140-7007(96)00073-4.

(76) Lemmon, E. W.; Huber, M. L.; McLinden, M. O. Reference Fluid Thermodynamic and Transport Properties-REFPROP. NIST Standard Reference Database 23, Version 9.1, DLL version number 9.1. U.S. Secretary of Commerce on behalf of the United States of America; 2013.

(77) Farris, C. B. Unusual Design Factors for Supercritical $\mathrm{CO}_{2}$ Pipelines. Energy Prog. 1983, $3(3), 150-158$.

(78) Mohitpour, M.; Jenkins, A.; Nahas, G. A generalized overview of requirements for the design, construction, and operation of new pipelines for $\mathrm{CO}_{2}$ sequestration. J. Pipeline Eng. 2008, 7 (4), 237-251. Web site. http://www.j-pipe-eng.com/Abstract.cfm?cat_no=2148s (accessed May 10, 2018). 
(79) Witkowski, A.; Rusin, A.; Majkut, M.; Rulic, S.; Stolecka, K. Comprehensive analysis of pipeline transportation systems for $\mathrm{CO}_{2}$ sequestration. Thermodynamics and safety problems. Energy Convers. Manag. 2013, 76, 665-673. https://doi.org/10.1016/j.enconman.2013.07.087 